\title{
In-cloud sulfate addition to single particles resolved with sulfur isotope analysis during HCCT-2010
}

\author{
E. Harris ${ }^{1}{ }^{*}$, B. Sinha ${ }^{1,2}$, D. van Pinxteren ${ }^{3}$, J. Schneider ${ }^{1}$, L. Poulain ${ }^{3}$, J. Collett ${ }^{4}$, B. D'Anna ${ }^{5}$, B. Fahlbusch ${ }^{4}$,

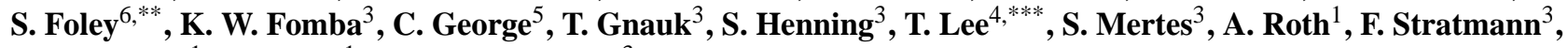 \\ S. Borrmann ${ }^{1}$, P. Hoppe ${ }^{1}$, and H. Herrmann ${ }^{3}$ \\ ${ }^{1}$ Particle Chemistry Department, Max Planck Institute for Chemistry, Hahn-Meitner-Weg 1, 55128 Mainz, Germany \\ ${ }^{2}$ Department of Earth Sciences, Indian Institute of Science Education and Research Mohali, Sector 81, SAS Nagar, Manauli \\ PO 140306, India \\ ${ }^{3}$ Leibniz-Institute for Tropospheric Research (TROPOS), Permoserstrasse 15, 04318 Leipzig, Germany \\ ${ }^{4}$ Department of Atmospheric Science, Colorado State University, Fort Collins, CO 80523, USA \\ ${ }^{5}$ Institute de recherches sur la catalyse et l'environnement de Lyon (IRCE Lyon), University of Lyon, \\ 69100 Villeurbanne, France \\ ${ }^{6}$ Earth System Science Research Centre, Institute for Geosciences, University of Mainz, Becherweg 21, \\ 55128 Mainz, Germany \\ *now at: Laboratory for Air Pollution and Environmental Technology, EMPA, Überlandstrasse 129, \\ 8600 Dübendorf, Switzerland \\ ** now at: Department of Earth and Planetary Science, ARC Centre for Core to Crust Fluid Systems, Building E7A, \\ Macquarie University, North Ryde, NSW 2109, Australia \\ ${ }^{* * *}$ now at: Department of Environmental Sciences, Hankuk University of Foreign Studies, Yongin, South Korea
}

Correspondence to: E. Harris (eliza.harris@empa.ch)

Received: 3 December 2013 - Published in Atmos. Chem. Phys. Discuss.: 28 January 2014

Revised: 28 March 2014 - Accepted: 7 April 2014 - Published: 28 April 2014

\begin{abstract}
In-cloud production of sulfate modifies aerosol size distribution, with important implications for the magnitude of indirect and direct aerosol cooling and the impact of $\mathrm{SO}_{2}$ emissions on the environment. We investigate which sulfate sources dominate the in-cloud addition of sulfate to different particle classes as an air parcel passes through an orographic cloud. Sulfate aerosol, $\mathrm{SO}_{2}$ and $\mathrm{H}_{2} \mathrm{SO}_{4}$ were collected upwind, in-cloud and downwind of an orographic cloud for three cloud measurement events during the Hill Cap Cloud Thuringia campaign in autumn 2010 (HCCT-2010). Combined SEM and NanoSIMS analysis of single particles allowed the $\delta^{34} \mathrm{~S}$ of particulate sulfate to be resolved for particle size and type.

The most important in-cloud $\mathrm{SO}_{2}$ oxidation pathway at HCCT-2010 was aqueous oxidation catalysed by transition metal ions (TMI catalysis), which was shown with single particle isotope analyses to occur primarily in cloud droplets nucleated on coarse mineral dust. In contrast, direct uptake
\end{abstract}

of $\mathrm{H}_{2} \mathrm{SO}_{4}(\mathrm{~g})$ and ultrafine particulate were the most important sources modifying fine mineral dust, increasing its hygroscopicity and facilitating activation. Sulfate addition to "mixed" particles (secondary organic and inorganic aerosol) and coated soot was dominated by in-cloud aqueous $\mathrm{SO}_{2}$ oxidation by $\mathrm{H}_{2} \mathrm{O}_{2}$ and direct uptake of $\mathrm{H}_{2} \mathrm{SO}_{4}(\mathrm{~g})$ and ultrafine particle sulfate, depending on particle size mode and time of day. These results provide new insight into in-cloud sulfate production mechanisms, and show the importance of single particle measurements and models to accurately assess the environmental effects of cloud processing.

\section{Introduction}

Sulfate-containing atmospheric particles have a significant but uncertain climatic effect through their role in radiative forcing (IPCC, 2013). They are also important as 
heterogeneous reaction surfaces and for acid deposition, human health and visibility (Seinfeld and Pandis, 1998). Incloud $\mathrm{SO}_{2}$ oxidation and production of sulfate aerosol mass results in significant modification of the aerosol size distribution and particle hygroscopicity, which is particularly important in controlling the lifetime and climatic effect of aerosol, health impacts, and the availability of trace metals. Understanding the effect of these changes on the magnitude of radiative forcing is essential to model the impact of anthropogenic $\mathrm{SO}_{2}$ emissions and sulfate aerosol on the past and future climate.

In-cloud mass addition occurs as particles enter a cloud and become activated to form cloud droplets. Upon leaving the cloud, the droplets evaporate to form single particles containing both the initial mass and the non-volatile aqueous phase products formed in the cloud, as droplets rarely break up during evaporation (Mitra et al., 1992). Mass is added to aerosols as they pass through clouds by a variety of processes, summarised in Table 1 along with abbreviations that will be used throughout this paper. The uptake of gas-phase species (DISS) such as $\mathrm{H}_{2} \mathrm{SO}_{4}, \mathrm{HCl}, \mathrm{HNO}_{3}$ and ammonia can contribute the majority of in-cloud mass gain in some conditions (Flynn et al., 2000), but the aqueous oxidation of $\mathrm{SO}_{2}$ to sulfate in cloud droplets (AQOX) is generally considered to be the most important in-cloud mass production pathway (Bradbury et al., 1999; Laj et al., 1997a, b; Mertes et al., 2005a). $\mathrm{SO}_{2}$ is oxidised to sulfate in the aqueous phase by $\mathrm{O}_{3}, \mathrm{H}_{2} \mathrm{O}_{2}$ and transition metal-catalysed oxidation by $\mathrm{O}_{2}$ (Sander et al., 1995; Bower et al., 1997). $\mathrm{H}_{2} \mathrm{O}_{2}$ is commonly modelled to be the most important in-cloud oxidant, due to the strong $\mathrm{pH}$ dependence of oxidation by $\mathrm{O}_{3}$, and the low concentrations of transition metals combined with the slower modelled rate of transition metal-catalysed oxidation (Bower and Choularton, 1993; Sander et al., 1995; Suhre et al., 2000; Hegg et al., 2004). However, recent results suggest transitionmetal ion catalysed oxidation (TMI-catalysis) was the dominant oxidation pathway in clouds at HCCT-2010, and is therefore strongly underestimated in models (Harris et al., 2013; Alexander et al., 2009).

In-cloud sulfate mass addition is not evenly distributed across the upwind aerosol population. CCN activity and activation depends on the size and hygroscopicity of particles, as well as the strength of the updraught, the wind speed and supersaturation, and other processes such as entrainment mixing of drier air (Mertes et al., 2005b; Kasper-Giebl et al., 2000; Bower and Choularton, 1993). Mass is only significantly added to those particles which are able to activate in the cloud, resulting in a bimodal size distribution with the Hoppel gap at 50-100 nm following cloud processing (Hoppel et al., 1986, 1994; Bradbury et al., 1999; Yuskiewicz et al., 1999). Once activated, the addition of sulfate is still size-dependent; for example, uptake of gas-phase sulfuric acid is expected to be most important for smaller droplets, which have a higher surface area to volume ratio and can take up gas-phase species much more efficiently than large droplets (Flynn et al., 2000).

$\mathrm{H}_{2} \mathrm{O}_{2}$ is often a limiting oxidant, thus it adds the majority of sulfate to those particles activated early in the cloud - the most efficient $\mathrm{CCN}$ - and has little effect on the downwind $\mathrm{CCN}$ number concentration. Entrainment often adds $\mathrm{H}_{2} \mathrm{O}_{2}$ later in the cloud, but as the entrained air is dry it can cause the smallest droplets to evaporate (Bower et al., 1997). Oxidation by $\mathrm{O}_{3}$ is strongly self-limiting as the oxidation rate decreases by several orders of magnitude below a $\mathrm{pH}$ of $\sim 5.5$ (Seinfeld and Pandis, 1998), thus it is most important for particles with the highest pH (Kreidenweis et al., 2003). Even in these particles, the $\mathrm{pH}$ limitation means that oxidation by $\mathrm{O}_{3}$ is a minor pathway unless a strong source of alkalinity or ammonia is present such as in the marine boundary layer (Redington et al., 2009). Oxidation by transition metal catalysis is less strongly $\mathrm{pH}$-dependent than oxidation by $\mathrm{O}_{3}$. The concentration of S(IV) available for oxidation is $\mathrm{pH}$-dependent and studies suggest reaction of $\mathrm{SO}_{3}^{2-}$ may be favoured over $\mathrm{HSO}_{3}^{-}$(Rani et al., 1992; Cohen et al., 1981), however the availability of metal ions is higher at lower $\mathrm{pH}$, and the rate constants for oxidation may peak around $\mathrm{pH} 4-6$, leading to a complex $\mathrm{pH}$ dependence which is not fully understood (Cohen et al., 1981; Ibusuki and Takeuchi, 1987). The oxidant $\left(\mathrm{O}_{2}\right)$ for TMI-catalysed oxidation is not limiting, however the concentration of transition metals present in cloud water depends on the composition of the nucleating particle, which varies with size and particle type (Brueggemann et al., 2005). Thus, the total amount of sulfate added in the cloud by both in-cloud "direct uptake" processes (DISS and SCAV) and in situ production $\left(\mathrm{SO}_{2}\right.$ oxidation; $\left.\mathrm{AQOX}\right)$ is not evenly distributed across the aerosol population. Bulk analyses cannot adequately resolve size-dependent alterations of size and hygroscopicity.

The radiative effect of cloud processing is also sizedependent. The direct aerosol effect involves climatic cooling of -0.3 to $-1 \mathrm{~W} \mathrm{~m}^{-2}$ due to scattering of solar radiation by particles (Jones et al., 1994; Boucher and Lohmann, 1995). Scattering is most efficient for particles in the size range of $0.3-0.8 \mu \mathrm{m}$, the wavelength of visible light, thus sulfate produced in clouds on pre-existing particles has a greater direct aerosol effect than the ultrafine particles formed from gas-phase $\mathrm{SO}_{2}$ oxidation (Hegg, 1994). Sulfate addition in clouds increases the magnitude of direct radiative forcing both by increasing particle size (dry diameter) and by increasing particle hygroscopicity (thus increasing wet diameter; Yuskiewicz et al., 1999). The scattering efficiency of the particle population can be increased by $>10-100 \%$ following cloud processing (Lelieveld and Heintzenberg, 1992; Yuskiewicz et al., 1999; Hegg et al., 2004).

The indirect aerosol effect refers to the increase in cloud condensation nuclei (CCN) number concentration due to anthropogenic activities, which results in smaller, more numerous cloud droplets for the same liquid water content (LWC), 
Table 1. Definitions and abbreviations (“Abb.”) for processes involving modification of particulate by sulfur species observed at HCCT-2010, after Seinfeld and Pandis (1998), p. 933. For in-cloud processes, effects on number concentration and mean diameter refer to the effect on the particle population following evaporation after an air particle leaves the cloud, i.e. downwind vs. upwind of a cloud. Processes CON, DISS, COAG and SCAV collectively involve direct transfer of sulfate from the gas-phase and ultrafine particle into a larger particle mode, and will be referred to as "direct uptake", which can occur both in and out of a cloud.

\begin{tabular}{|c|c|c|c|c|}
\hline \multirow[t]{2}{*}{ Process } & \multirow[t]{2}{*}{ Abb. } & \multirow[t]{2}{*}{ Description } & \multicolumn{2}{|c|}{ Effect on: } \\
\hline & & & Number conc. & Mean diameter \\
\hline Condensation & $\mathrm{CON}$ & $\begin{array}{l}\text { Phase transfer of gaseous } \mathrm{H}_{2} \mathrm{SO}_{4} \text { to } \\
\text { the solid (particle) or semisolid phase }\end{array}$ & None & Increase \\
\hline Uptake (dissolution) & DISS & $\begin{array}{l}\text { Dissolution of } \mathrm{H}_{2} \mathrm{SO}_{4} \text { into a } \\
\text { cloud droplet or a liquid particle }\end{array}$ & None & Increase \\
\hline Impaction scavenging & SCAV & $\begin{array}{l}\text { Collision and combination of an interstitial } \\
\text { particle with a cloud droplet }\end{array}$ & Decrease & Increase \\
\hline Coagulation & COAG & $\begin{array}{l}\text { Collision and combination of two smaller } \\
\text { particles to form one larger particle }\end{array}$ & Decrease & Increase \\
\hline Cloud droplet nucleation & NUC & $\begin{array}{l}\text { Formation of a cloud droplet on a CCN, and } \\
\text { dissolution of CCN components (eg. sulfate) }\end{array}$ & None & None \\
\hline Aqueous oxidation & AQOX & $\begin{array}{l}\text { Dissolution and oxidation of } \mathrm{SO}_{2} \text { in the } \\
\text { aqueous phase (cloud droplet) }\end{array}$ & None & Increase \\
\hline
\end{tabular}

and thus increased cloud albedo and lifetime (Twomey, 1991; Boucher and Lohmann, 1995). The magnitude of forcing from the indirect effect is highly uncertain due to the complex and nonlinear relationships between sulfate concentration, $\mathrm{CCN}$ number and cloud droplet number concentration (Twomey, 1991; Jones et al., 1994; Boucher and Lohmann, 1995). The effect of sulfate addition on CCN concentration is most significant for the smallest, least hygroscopic particles, which need only a small sulfate addition to be significantly more active as CCN (Bower and Choularton, 1993). Eventually all processed particles can already act as efficient $\mathrm{CCN}$, thus the effect of cloud processing on indirect radiative forcing is most important for freshly released particles; processing of aged aerosol primarily affects direct radiative forcing. In addition, changes in $\mathrm{pH}$, hygroscopicity and other parameters are important for aerosol lifetime, health effects and trace metal availability (Nel, 2005; Pope and Dockery, 2006; Jickells et al., 2005).

\section{Sulfur isotopes in the environment}

Measurement of stable sulfur isotope abundances is the only technique available that can directly distinguish between sulfate produced by different reaction pathways. The environmental and climatic effects of sulfate addition are not adequately described by bulk measurements: the processes contributing mass need to be resolved for particle type and size to determine how in-cloud mass production alters aerosol size distributions and properties. Recent models studies have confirmed the large errors introduced by size- and composition-averaging in models of aerosol aging (Riemer et al., 2009; Ching et al., 2012). Sulfur isotope analysis with the NanoSIMS (Secondary Ion Mass Spectrometry), combined with Scanning Electron Microscopy (SEM) measurements, will allow the first single-particle view of in-cloud sulfate mass production.

Sulfur isotope abundances are described with the delta notation, which is the permil deviation of the ratio of a heavy isotope to the most abundant isotope $\left({ }^{32} \mathrm{~S}\right)$ in the sample compared to a standard ratio:

$\delta^{x} \mathrm{~S}=\left[\frac{\left(\frac{n\left({ }^{x} \mathrm{~S}\right)}{n\left({ }^{32} \mathrm{~S}\right)}\right)_{\text {sample }}}{\left(\frac{n\left({ }^{x} \mathrm{~S}\right)}{n\left({ }^{32} \mathrm{~S}\right)}\right)_{\mathrm{V}-\mathrm{CDT}}}-1\right] \times 1000$,

where $n$ is the number of atoms, ${ }^{x} \mathrm{~S}$ is one of the heavy isotopes, ${ }^{33} \mathrm{~S},{ }^{34} \mathrm{~S}$ or ${ }^{36} \mathrm{~S}$, and V-CDT is the international sulfur isotope standard, Vienna Canyon Diablo Troilite, which has isotopic ratios of ${ }^{34} \mathrm{~S} /{ }^{32} \mathrm{~S}=0.044163$ and ${ }^{33} \mathrm{~S} /{ }^{32} \mathrm{~S}=$ 0.007877 (Ding et al., 2001). Isotope fractionation is characteristic for reactions, thus isotopic measurements can be used to distinguish between different reaction pathways, such as the different oxidation pathways for $\mathrm{SO}_{2}$. Kinetic isotopic fractionation is represented by the fractionation factor $(\alpha)$, which is the ratio of the heavy to the light isotope amount in the instantaneously formed product divided by the ratio in the reactant:

$\alpha_{34}=\frac{\left(\frac{n\left({ }^{34} \mathrm{~S}\right)}{n\left({ }^{32} \mathrm{~S}\right)}\right)_{\text {products }}}{\left(\frac{n\left({ }^{34} \mathrm{~S}\right)}{n\left({ }^{32} \mathrm{~S}\right)}\right)_{\text {reactants }}}$.

Values of $\alpha_{34}$ for the major oxidation pathways - such as oxidation by $\mathrm{OH}, \mathrm{H}_{2} \mathrm{O}_{2}, \mathrm{O}_{3}$ and transition metals - have been measured, as shown in Table 2 (Harris et al., 2012b, 2014). 
Table 2. Sulfur isotope fractionation factors for the major known continental atmospheric $\mathrm{SO}_{2}$ oxidation pathways. $\epsilon_{34}=\left(\alpha_{34}-1\right) \times$ 1000 ; i.e. $\epsilon_{34}$ is an expression of $\alpha_{34}$ in \%o. Reaction types: Gas $=$ gas phase, $\mathrm{AQ}=$ aqueous, $\mathrm{SURF}=$ surface oxidation on mineral dusts, possibly with $\mathrm{O}_{3}$ as an oxidant, as described in Harris et al. (2012a). References: (1) Harris et al. (2014), (2) Harris et al. (2012b), (3) Harris et al. (2012a).

\begin{tabular}{llrrr}
\hline Oxidant & Type & $\begin{array}{r}\epsilon_{34} \text { at } \\
\sim 20{ }^{\circ} \mathrm{C} \% 0\end{array}$ & $\begin{array}{r}T \text { dependence } \\
\% 0^{\circ} \mathrm{C}^{-1}\end{array}$ & Ref. \\
\hline $\mathrm{OH}$ & Gas & $10.5 \pm 0.7$ & $-0.004 \pm 0.015$ & $(1)$ \\
$\mathrm{Criegee}$ & $\mathrm{Gas}$ & Unknown & & \\
$\mathrm{H}_{2} \mathrm{O}_{2}$ & $\mathrm{AQ}$ & $14.8 \pm 0.2$ & $-0.085 \pm 0.004$ & $(1)$ \\
$\mathrm{O}_{3}$ & $\mathrm{AQ}$ & $17.4 \pm 2.8$ & Unknown & $(2)$ \\
$\mathrm{O}_{2}$ (TMI-catalysis) & AQ & $-9.8 \pm 0.04$ & $-0.237 \pm 0.004$ & $(1)$ \\
Unknown & SURF & $9.6 \pm 3.6$ & Unknown & $(3)$ \\
\hline
\end{tabular}

The fractionation factor for the recently identified gas-phase oxidation pathway involving Criegee radicals (Mauldin et al., 2012; Boy et al., 2013) has not yet been measured. Isotopic analyses are particularly useful to quantify the importance of transition-metal catalysed oxidation of $\mathrm{SO}_{2}$ compared to oxidation by $\mathrm{H}_{2} \mathrm{O}_{2}$ in clouds, as TMI-catalysed oxidation is the only known pathway that produces negative isotope fractionation in continental environments, as shown in Table 2 (Harris et al., 2013).

This study presents measurements of sulfur isotope abundances in $\mathrm{SO}_{2}$ and $\mathrm{H}_{2} \mathrm{SO}_{4}$ gas and in particulate matter upwind, in-cloud, and downwind of an orographic cloud during the Hill Cap Cloud Thuringia (HCCT-2010) campaign. Isotope ratios were measured with the NanoSIMS, which allowed different particle sizes and types to be resolved. The gas-phase results unexpectedly showed that transition metal-catalysed oxidation of $\mathrm{SO}_{2}$ was the most important in-cloud $\mathrm{SO}_{2}$ oxidation pathway (Harris et al., 2013). This paper presents the particulate isotope measurements, which are used to determine the dominant process contributing sulfate mass to different particle classes in the cloud. The results show that there is significant variation in the dominant sulfate source with particle size and type.

\section{Experimental}

\subsection{Measurement conditions}

\subsubsection{Site description}

Field measurements were carried out in the Thüringer Wald in central Germany in autumn 2010. The site is located on a low mountain ridge which extends for around $60 \mathrm{~km}$ in a southeast to northwest direction. Southwesterly winds are forced to cross the ridge which often results in orographic cloud formation as air parcels are lifted and supersaturations are reached. Measurements were taken at three stations: (i) the upwind station "Goldlauter" (605 ma.s.l.) is located around $3 \mathrm{~km}$ southwest of the in-cloud station at Schmücke, (ii) the in-cloud measurement station is located at the Umweltbundesamt (Federal Environment Agency) mountain station "Schmücke" at a height of $937 \mathrm{~m}$ a.s.l., and (iii) the downwind station "Gehlberg" (732 m a.s.l.) is around $3 \mathrm{~km}$ to the northeast of Schmücke. The geography of the site means that southwesterly winds cause air parcels to pass through the three stations in series.

\subsubsection{Full cloud events}

Hill cap cloud measurements (FCE; "Full Cloud Event") were taken when the following conditions were met: the liquid water content at Schmücke was $>0.1 \mathrm{~g} \mathrm{~m}^{-3}$, the wind direction was between $200^{\circ}$ and $250^{\circ}$ (for connected flow between the sites), the wind speed was between 2 and $12 \mathrm{~m} \mathrm{~s}^{-1}$, the valley stations were free of fog and all sites were free of precipitation, the temperature was $>0^{\circ} \mathrm{C}$, and the local meteorological conditions were stable.

Connected flow between sites was investigated with ozone concentration profiles, ozone cross-correlations and hydrodynamic flow analysis, as ozone is quasi-chemically inert and relatively insoluble in water with no significant primary sources (Tilgner et al., 2014). The coefficients of divergence (COD) for several aerosol particle bins and ozone concentrations were also calculated to characterise connected flow conditions. The COD is a statistical measure of temporal similarities between the concentrations measured at the different stations; lower COD values indicate very similar concentration profiles, and a COD of $<0.1-0.2$ can be used as an indication of homogeneity between sites (Tilgner et al., 2014; USEPA, 2004). In addition, connected flow between the sites was periodically measured with tracer experiments following the release of an inert gas $\left(\mathrm{SF}_{6}\right)$ at Goldlauter, with measurements at $5 \mathrm{~min}$ intervals at nine sites including the in-cloud and downwind stations. The connected flow analyses are discussed in detail in a companion paper in this special issue of Atmospheric Chemistry and Physics (Tilgner et al., 2014).

Samples for sulfur isotope analysis were collected during three of the cloud events that occurred during HCCT-2010. The sampling times and meteorological conditions are shown in Table 3. The HYSPLIT (NOAA Air Resources Laboratory) back trajectories for the three cloud events are shown in Fig. 1 compared to the $\mathrm{SO}_{2}$ emission strength (CEIP, 2010). The concentration of $\mathrm{SO}_{2}$ was higher in the events FCE 11.2 and 11.3 than in FCE 7.1. This can be attributed to the back trajectories, which passed over the high-emission region to the southeast of the measurement area. Temperature and other meteorological parameters were similar across the three events.

\subsubsection{Non-cloud measurements}

One sample was collected when no hill cap cloud was present at Schmücke (NC; "non-cloud"), for comparison with the 
Table 3. Measurement periods for sulfur isotope analysis during the HCCT-2010 campaign. Times are Central European Summer Time (CEST). Liquid water content and temperature (at Schmücke) and upwind $\left[\mathrm{SO}_{2}\right]$ represent average values for the measurement period. Connected flow analyses are only available for cloud events.

\begin{tabular}{lllrrrl}
\hline Name & Type & Sampling times & $\begin{array}{r}\text { LWC } \\
\mathrm{g} \mathrm{m}^{-3}\end{array}$ & $\begin{array}{r}T \\
{ }^{\circ} \mathrm{C}\end{array}$ & $\begin{array}{r}{\left[\mathrm{SO}_{2}\right] \text { upwind }} \\
\mathrm{nmol} \mathrm{m}^{-3}\end{array}$ & Connected flow \\
\hline NC 1 & non-cloud, day & 08:30 29.09.10-16:00 29.09.10 & $<0.1$ & & 5.8 & Poor, northwest flow \\
FCE 7.1 & cloud, night & 23:45 24.09.10-01:45 25.09.10 & 0.14 & 8.3 & 7.1 & Good for half of event \\
FCE 11.2 & cloud, night & 22:30 01.10.10-05:30 02.10.10 & 0.37 & 6.2 & 12.0 & Good for whole event \\
FCE 11.3 & cloud, day & 14:30 02.10.10-20:00 02.10.10 & 0.32 & 7.7 & 9.8 & Good for whole event \\
\hline
\end{tabular}
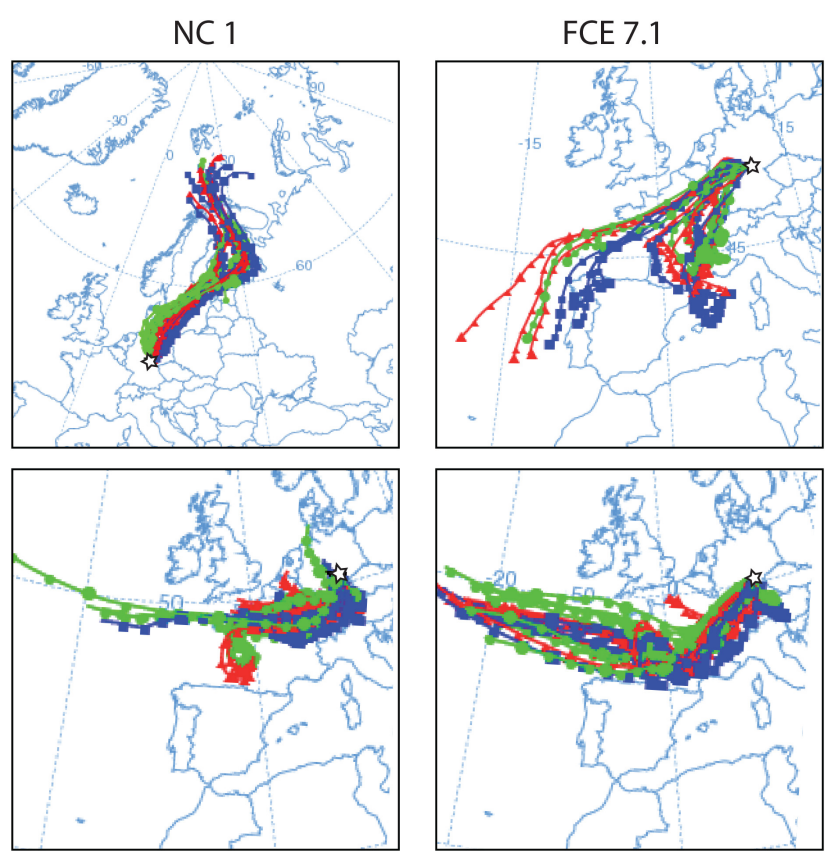

FCE 11.2

FCE 11.3

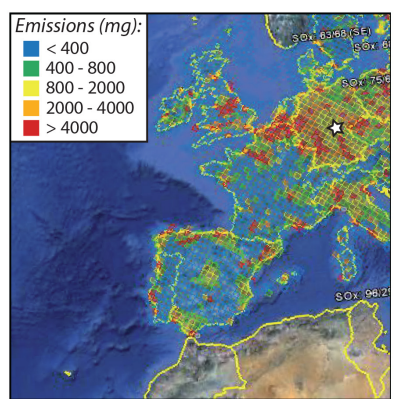

Fig. 1. Air mass back trajectories for cloud events at the HCCT2010 campaign. Emissions are in $\mathrm{Mg}\left(10^{6} \mathrm{~g}\right)$ and are from the Centre on Emission Inventories and Projections (CEIP, 2010)

cloud events. LWC was $<0.1 \mathrm{~g} \mathrm{~m}^{-3}$ at Schmücke although there were high clouds present. The details of the event are shown in Table 3 and the back trajectory in Fig. 1. The noncloud measurement period does not present a perfect comparison to the cloud events as the wind was northeasterly rather than southwesterly; thus flow will proceed from Gehlberg over Schmücke to Goldlauter. The connected flow conditions were poor during the non-cloud event, thus the individual station values can be considered but comparison between stations should be carefully considered. No better non-cloud period with southwest winds occurred during the sulfur isotope measurement period (which was shorter than the full HCCT-2010 campaign), thus this time frame represents the best possible comparison. For the rest of the paper, stations will simply be referred to as upwind, in-cloud/mountain and downwind for clarity.

\subsection{Particulate sampling}

Particulate samples were collected on filter packs at all three measurement stations, however they were unfortunately not collected during FCE 7.1 due to equipment problems. Nuclepore track-etch polycarbonate membrane filters (Whatman Ltd), which had been coated with a $10 \mathrm{~nm}$-thick gold layer using a sputter coater (Bal-tec $\mathrm{GmbH}$, Model SCD-050) prior to sample collection, were used to collect particulate samples. Coarse and fine particles were collected on filters with $5 \mu \mathrm{m}$ and $0.2 \mu \mathrm{m}$ pores respectively. The calculated $50 \%$ cutoff diameters at $1 \mathrm{~L} \mathrm{~min}^{-1}$ flow rate are $1.9 \mu \mathrm{m}$ and $60 \mathrm{~nm}$ for coarse and fine filters respectively (John et al., 1983), which is in good agreement with the SEM-measured lower cut-off diameter of $50 \mathrm{~nm}$ for fine particles (Sinha et al., 2014a). The effective cut-off between the coarse and fine filters found from SEM measurements is around $600 \mathrm{~nm}$, with tails in both directions caused by the random distribution of pores across the filter and variations in particle density and shape (Sinha et al., 2014a). Traditional definitions of coarse/fine particulate (coarse particles $>1 \mu \mathrm{m}>$ fine particles) are therefore not exactly represented by the filter cut-off diameters. SEM measurements of particle diameter were used to refine the division of coarse and fine particulate: whenever only particles $<1 \mu \mathrm{m}$ were encountered for a particular particle type in a particular sample, particles on both filters were combined and classified as fine; for particle classes where both "coarse" $(>1 \mu \mathrm{m})$ and "fine" $(<1 \mu \mathrm{m})$ particles were encountered in a given sample, the fine and coarse filters are used as a guide to the size dependency of different processes in the discussion in Sect. 5. 
At the in-cloud measurement site, interstitial (nonactivated) particles and cloud droplet residuals (particulate matter from evaporated cloud droplets) were collected separately with a counterflow virtual impactor (CVI) and a complementary droplet-segregating interstitial inlet (INT) (Schwarzenboeck et al., 2000; Mertes et al., 2005b). The system had an operationally defined discrimination diameter of $5 \mu \mathrm{m}$ for separation of the two aerosol populations. Particles with a dry diameter $>5 \mu \mathrm{m}$ (mineral dust) would be included in the cloud droplet residual fraction whether they were activated or not. The largest mineral dust particles - which could have erroneously been collected as "cloud droplet residuals" - were however not analysed, to prevent artefacts due to electrostatic charging, which would affect the correction of the instrumental mass fractionation during NanoSIMS analysis (Winterholler et al., 2008).

\subsection{Gas-phase sulfur sampling}

After particulate was removed from the sampling air flow, $\mathrm{SO}_{2}$ and sulfuric acid gases were collected for isotopic analysis at the upwind and downwind sites. A detailed description and validation of the collection methods is presented in Harris et al. (2012b) and only a brief description will be given here. Sulfuric acid gas was collected from the flow first, in glass vessels with a high internal surface area. This does not represent pure $\mathrm{H}_{2} \mathrm{SO}_{4}$ (g) but will primarily contain ultrafine and freshly nucleated particles; as the $50 \%$ cut-off diameter of the fine filters is $\sim 50 \mathrm{~nm}$, sulfate particulate below this size will contribute to the "sulfuric acid" measurement. The collection efficiency for the sulfuric acid collectors is $\sim 100 \%$ so no isotopic fractionation is introduced.

$\mathrm{SO}_{2}$ was collected in a bubbler containing $6 \% \mathrm{H}_{2} \mathrm{O}_{2}$. The $\mathrm{H}_{2} \mathrm{O}_{2}$ solutions were prepared freshly immediately before beginning collection. The collection efficiency is $39 \%$ and a fractionation of $+11.5 \pm 1.3 \%$ is introduced, which is corrected for in all results presented in this paper. Following an event $(2-8 \mathrm{~h})$ the flow to the collectors was turned off. Less than three hours after the end of sampling the two collectors were rinsed with Milli-Q water into clean sample jars and $\mathrm{BaCl}_{2}$ was added to precipitate sulfate as $\mathrm{BaSO}_{4}$. The $\mathrm{BaSO}_{4}$ was later collected for NanoSIMS and SEM analysis by filtering the samples through gold-coated Nuclepore filters with $0.2 \mu \mathrm{m}$ pores.

\subsection{SEM analysis}

Scanning electron microscope (SEM) measurements were used to classify different particle types and investigate their chemical composition. The samples could be directly analysed in the SEM after collection on gold-coated filters without any further treatment. A LEO 1530 field emission SEM with an Oxford Instruments ultra-thin-window energydispersive X-ray detector (EDX) was run in automatic mode, taking regularly spaced images of the coarse and fine filters at $6500 \times$ and $19500 \times$ magnification respectively. The SEM was operated with an accelerating voltage of $15 \mathrm{keV}$, a $60 \mu \mathrm{m}$ aperture and a working distance of $9.6 \mathrm{~mm}$. "High current mode" was used to increase the EDX signal and improve elemental sensitivity. The SEM automatic analysis leaves a grid pattern on the gold-coated filters that is visible in the CCD camera of the NanoSIMS, which allows NanoSIMS and SEM images of the filters to be matched. The SEM images of the filters were also used to calculate size distributions for the different particle types to investigate properties important for CCN activity (Sinha et al., 2014a).

\subsection{NanoSIMS analysis}

Following automatic analysis in the SEM, the sulfur isotopic composition of the particles was determined with the Cameca NanoSIMS 50 ion probe at the Max Planck Institute for Chemistry in Mainz (Hoppe, 2006; Groener and Hoppe, 2006). The NanoSIMS 50 has a high lateral resolution $(<100 \mathrm{~nm})$ and high sensitivity and can simultaneously measure up to five different masses through a multicollection system, allowing high-precision isotope analysis of single particles. Two types of NanoSIMS analysis were used in this study: an image analysis, where the counts of the various ions are recorded at each point of the raster to create an image of the ion intensity, such as that shown in Fig. 2, and an isotope analysis, where the counts are integrated across the raster area to obtain an accurate value for the isotope ratios. Image analyses were used only to identify particle types (Sect. 3.6), not to calculate $\delta^{34} \mathrm{~S}$ values. The use of this instrument to analyse sulfur isotope ratios in the isotope ratio analysis mode is described in detail in Winterholler et al. (2006, 2008) and analysis conditions similar to those used for the current study are given in Harris et al. (2012b), so only a brief description will be included here.

The particulate samples and the $\mathrm{BaSO}_{4}$ from the gas samples can be analysed directly on the gold-coated filters without further processing. $\mathrm{A} \sim 1 \mathrm{pACs}^{+}$beam is focused onto a $\sim 100 \mathrm{~nm}$ sized spot and rastered in a $2 \mu \mathrm{m} \times 2 \mu \mathrm{m}$ grid over the grain of interest. The ejected secondary ions are carried into the mass spectrometer and multicollection system. Each measurement consists of $<400$ cycles of 4.096 s duration preceded by varying lengths of presputtering until the count rate is stable. Very small particles are quickly completed sputtered away, so some analyses can be as short as 50 cycles. Presputtering is carried out on an area of at least $10 \mu \mathrm{m} \times 10 \mu \mathrm{m}$ to conserve sulfate for analysis. For particulate samples, secondary ions of ${ }^{16} \mathrm{O}^{-},{ }^{12} \mathrm{C}_{2}^{-},{ }^{26} \mathrm{CN}^{-},{ }^{32} \mathrm{~S}^{-}$ and ${ }^{34} \mathrm{~S}^{-}$were measured, to allow identification of particle type (Sect. 3.6). For the $\mathrm{BaSO}_{4}$ samples from gas-phase sulfur, some samples were measured for secondary ions of ${ }^{16} \mathrm{O}^{-},{ }^{12} \mathrm{C}_{2}^{-},{ }^{26} \mathrm{CN}^{-},{ }^{32} \mathrm{~S}^{-}$and ${ }^{34} \mathrm{~S}^{-}$and some for ${ }^{16} \mathrm{O}^{-}$, ${ }^{32} \mathrm{~S}^{-},{ }^{33} \mathrm{~S}^{-},{ }^{34} \mathrm{~S}^{-}$and ${ }^{36} \mathrm{~S}^{-}$. In both cases the ${ }^{34} \mathrm{~S} /{ }^{32} \mathrm{~S}$ ratio was measured with equal precision. The five secondary 

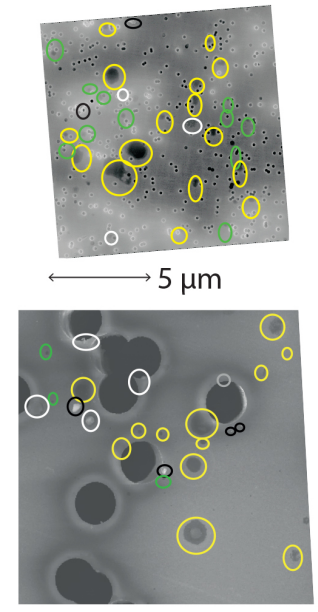

$\longleftrightarrow 5 \mu \mathrm{m}$
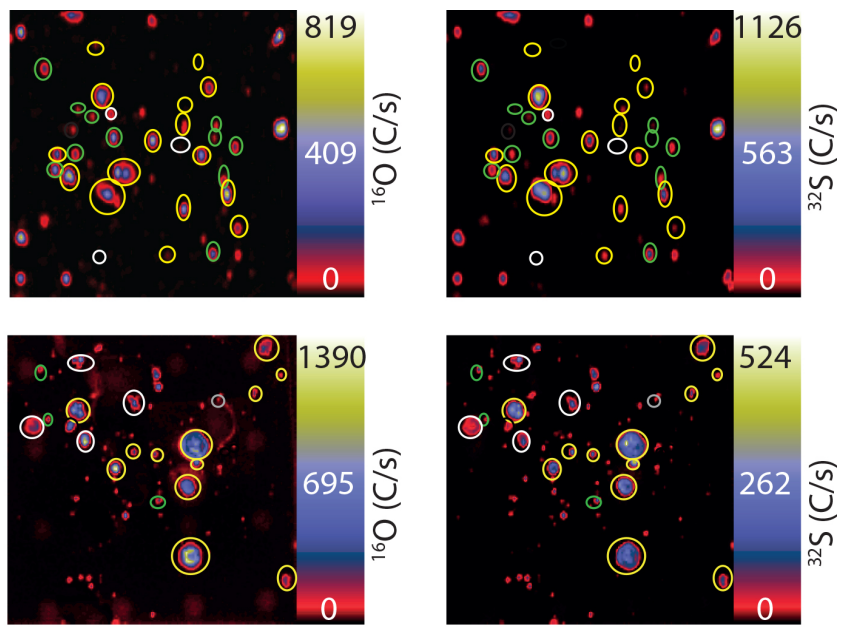

Fig. 2. SEM and NanoSIMS images of the same area on a fine (top) and coarse (bottom) particulate filter. Particles are circled with different colours according to particle type: yellow $=$ mixed particle, green $=$ organic aerosol, black $=$ soot, white $=$ soot + coating .

ion types were simultaneously detected in five electron multipliers at high mass resolution $\left(\mathrm{M} / \Delta \mathrm{M}>3900\right.$ for $\left.{ }^{33} \mathrm{~S}\right)$.

Mass-dependent and mass-independent instrumental mass fractionation (IMF) can occur at several stages of the NanoSIMS analysis, so the IMF correction factor in each measurement session is determined with the commercially available $\mathrm{BaSO}_{4}$ isotope standards IAEA-SO5 and IAEASO6. The IMF of the particles is also dependent on their matrix. The IMF correction factors for different matrices relative to $\mathrm{BaSO}_{4}$ from Winterholler et al. (2008) were used to correct for matrix-dependent IMF on the different particle types. The method for determining particle type is presented in Sect. 3.6. Organic aerosol particles containing inorganic salts, hereafter referred to as "mixed particles", with an $\mathrm{O} / \mathrm{S}$ ratio (measured in the NanoSIMS) of $<2$ were considered to be "organic" and were corrected with the IMF for cysteine $\left(-13.5 \pm 1.7 \%\right.$ relative to $\left.\mathrm{BaSO}_{4}\right)$. The most abundant cations in "inorganic" mixed particles $(\mathrm{O} / \mathrm{S}>3$ in NanoSIMS) were found from the SEM-EDX analysis to be $\mathrm{Na}$ and $\mathrm{K}$, so these particles were corrected by weighting the individual IMFs for $\mathrm{Na}$ and $\mathrm{K}$ by their abundances $\left(-8.4 \pm 2.7 \%\right.$ o relative to $\left.\mathrm{BaSO}_{4}\right)$. Mixed particles with an $\mathrm{O} / \mathrm{S}$ ratio between 2 and 3 were corrected by assuming they consisted of a mixture of organic and inorganic sulfates, thus the average IMF for organic and inorganic mixed particles of $-11.0 \pm 3.2 \%$ o relative to $\mathrm{BaSO}_{4}$ was used. Coated soot particles were corrected for matrix-dependent IMF in the same manner as the mixed particles. Chlorine was enriched on the mineral dust particle surfaces, suggesting the presence of condensed salts, which could supply cations to form sulfate salts. The cations within the dust are likely to be tightly bound and not available to interact with sulfate. As with the inorganic mixed particles, $\mathrm{Na}$ and $\mathrm{K}$ were found to be the most important cations and the abundance-weighted
IMF was used $\left(-8.4 \pm 3.7 \%\right.$ o relative to $\mathrm{BaSO}_{4}$; the error is higher than for the mixed particle IMF as less mineral dust particles were measured).

The number of counts is assumed to follow a Poisson distribution, so the counting statistical error is $\sqrt{n}$, i.e. the relative error is $1 / \sqrt{n}$ (Bevington and Robinson, 1992). The uncertainty in the isotopic composition of $\mathrm{BaSO}_{4}$ from gas-phase sulfate was calculated as described in Harris et al. (2012b). Some spot-to-spot variation is also seen between individual measurements on a filter, most likely due to topographic effects or nanoscale inhomogeneity, and this must be accounted for in the particulate measurements. The spot-to-spot error of the SO5 and SO6 standards was used as an estimate of the spot-to-spot error for the measurement session, and this was then combined with the counting statistical error to determine the measurement uncertainty for each individual grain. The error in the matrix-specific IMF was also included in the error for each grain. For each individual grain, the counting statistical error was typically $5-7 \%$ and the overall error 7-8\%. The weighted average of individual grain values was used as the average $\delta^{34} \mathrm{~S}$ for each particle class, with the uncertainty in the mean multiplied by $\sqrt{\chi^{2}}$ when $\chi^{2}>1$ within the particle group.

\subsection{Classification of particle types}

The different particle types present in the HCCT-2010 samples were investigated in both the SEM and the NanoSIMS to develop a classification method that would allow particle types to be identified with only the major element count rate ratios from NanoSIMS isotope analyses. This meant that the particles with the highest sulfur count could be selected in the NanoSIMS real time image, resulting in isotopic analysis with the smallest uncertainty, without the constraint of only 


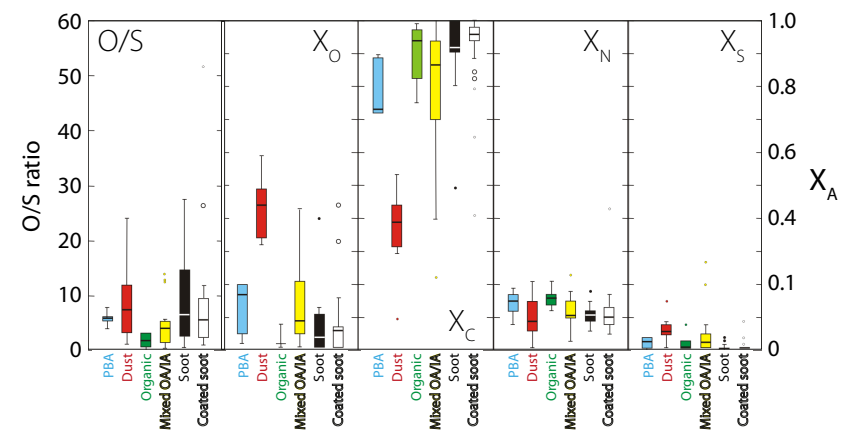

Fig. 3. Characteristic ratios of major elements measured with NanoSIMS used for chemical separation of different particle types for upwind and interstitial aerosol. Boxes indicate the 25-75 percentile ranges. Whiskers indicate the range until the last value that falls within the median $\pm 2 \sigma$ range. Large and small circles are outliers and lie outside $\pm 2 \sigma$ sigma and $\pm 3 \sigma$ sigma range respectively. The $\mathrm{O} / \mathrm{S}$ ratio is shown on the left-hand axis, while the molar ratios of $\mathrm{O}, \mathrm{C}, \mathrm{N}$ and $\mathrm{S}\left(X_{\mathrm{A}}\right)$ are shown on the right-hand axis. $\mathrm{PBA}=$ primary biological aerosol, $\mathrm{OA}=$ organic aerosol, $\mathrm{IA}=$ inorganic aerosol.

measuring the isotope ratios of particles for which there is an SEM image. Taking the SEM image after the NanoSIMS analysis is only possible for the largest and most robust particles; most particles are completely sputtered away during the NanoSIMS analysis.

Major elements ratios $\left({ }^{16} \mathrm{O},{ }^{12} \mathrm{C}_{2},{ }^{26} \mathrm{CN}\right.$ and $\left.{ }^{32} \mathrm{~S}\right)$ measured in the NanoSIMS were characterised for the different particle types by matching SEM and NanoSIMS images from ten coarse and five fine particulate filters. Two examples of matched SEM and NanoSIMS images are shown in Fig. 2. Five particle types were identified from the SEM images based on morphological characteristics and EDX signal: organic aerosol, mixed particles (with organic and inorganic components), mineral dust, soot and soot with a coating. The major element ratios were converted to molar fractions (Sinha et al., 2014b):

$X_{\mathrm{A}}=\frac{n_{\mathrm{A}}}{n_{\mathrm{O}}+n_{\mathrm{C}}+n_{\mathrm{N}}+n_{\mathrm{S}}}$,

where $\mathrm{A}=\mathrm{O}, \mathrm{C}, \mathrm{N}$ or $\mathrm{S}$. The characteristic ranges of $X_{\mathrm{A}}$ for the five different particle types are shown in Fig. 3. Using these characteristic ranges as well as the ratio of oxygen to sulfur signals $(\mathrm{O} / \mathrm{S})$, it was possible to distinguish the different particle types from a NanoSIMS isotopic analysis without a corresponding SEM image. The distinction between OA/IA, soot and coated soot is challenging as there is a high degree of overlap in most ratios; however, when all the ratios are used in combination all the particles used for isotopic analysis were able to be definitively categorised. Ratios $X_{\mathrm{O}}, X_{\mathrm{C}}$ and $X_{\mathrm{S}}$ are particularly useful to distinguish between mixed OA/IA and coated soot.

The most overlap is between pure organic aerosol and mixed particles, indicating that the SEM is not a suitable tool to detect small amounts of inorganic material in organic particles. Many salts present in fine mode aerosol are highly volatile under the electron beam (e.g. most salts of ammonium) but more stable under $\mathrm{Cs}^{+}$bombardment (Winterholler et al., 2008). Therefore, we will treat all organic and mixed particles as mixed and consisting of secondary organic (SO) and secondary inorganic (SI) material in variable proportions, even if no SI fraction is visible in the SEM. The accuracy of the classification method was tested on 21 particles which were all found in the SEM and the NanoSIMS and had sufficient sulfur counts for an isotopic analysis. These 21 particles were not used when defining the characteristic ranges of the ratios, thus they present a robust and independent test of the classification method. Nineteen of the 21 particles were correctly identified using the ratios, thus the classification is $>90 \%$ successful.

\subsection{Other measurements}

In addition to sulfur samples for isotopic analysis, a wide variety of other measurements were taken during the campaign (see van Pinxteren et al., 2011). A brief description of the measurement techniques for all measurements discussed in this paper will be given here; more details can be found in the accompanying papers in this special issue.

- $\mathrm{SO}_{2}$ concentration was measured with a time resolution of one minute using a Thermo Environmental trace level pulsed fluorescence $\mathrm{SO}_{2}$ analyser (model TE43C-TL) at Gehlberg and Goldlauter and an MLU enhanced trace level $\mathrm{SO}_{2}$ analyzer (model 43i-) at Schmücke.

- $\mathrm{O}_{3}$ concentration was measured with a time resolution of one minute using a Thermo Environmental U.V. Photometric Gas Analyzer (model TE49C-TL) at Gehlberg and Goldlauter and a Horiba Ambient Ozone Monitor (model APOA 360) at Schmücke.

- Cloud water was collected with a Caltech Active Strand Cloud Water Collector (CASCC) with an hourly sampling routine (Moore et al., 2004a, b).

- Transition metal ions were measured in cloud water and impactor samples using ion chromatography with UV-VIS detection and total reflective X-ray fluorescence (TXRF) respectively; details of the methods are given in Harris et al. (2013).

- $\mathrm{H}_{2} \mathrm{O}_{2}$ was measured in cloud water collected with a three-stage CASCC using a fluorescence spectrophotometer to detect the POPHA- $\mathrm{H}_{2} \mathrm{O}_{2}$ dimer (Moore et al., 2004a, b; Harris et al., 2013).

- Particulate composition was measured with aerosol mass spectrometry (AMS): a C-ToF-AMS was used for the cloud droplet residual fraction and an HRToF-AMS for the interstitial fractionation at Schmücke 
(Aerodyne Research, Inc.). Cloud droplet residual composition was also measured with a single particle laser ablation aerosol mass spectrometer (ALABAMA) at Schmücke.

- Cloud condensation nucleus (CCN) activity at different supersaturations $(0.07,0.1$ and $0.2 \%)$ upwind and downwind of the cloud was measured with a streamwise thermal gradiation CCN counter (Roberts and Nenes, 2005). Further details can be found in a companion paper (Henning et al., 2013).

\section{Production and processing of $\mathrm{SO}_{2}$ and $\mathrm{H}_{2} \mathrm{SO}_{4}$ gas and ultrafine sulfate particulate}

\section{1 $\mathrm{SO}_{2}$ oxidation}

$\mathrm{SO}_{2}$ oxidation and removal during the three cloud events at HCCT-2010 is discussed in detail in Harris et al. (2013), so only a summary of results will be given here. $\mathrm{SO}_{2}$ concentration and isotopic composition upwind and downwind of the cloud, shown in Fig. 4, was used to calculate fractionation factors for $\mathrm{SO}_{2}$ removal in the cloud $\left(\alpha_{\text {cloud }}\right)$. The calculated values of $\alpha_{\text {cloud }}$ were compared to fractionation factors measured in the laboratory for different oxidation pathways to show that (Harris et al., 2013):

- during FCE 7.1 oxidation by $\mathrm{H}_{2} \mathrm{O}_{2}$ in cloud droplets was the major $\mathrm{SO}_{2}$ removal process;

- during FCE 11.2 and 11.3 oxidation by transition metal catalysis, involving transition metal ions primarily from natural mineral dust, was the major $\mathrm{SO}_{2}$ removal process;

- the major $\mathrm{SO}_{2}$ removal process does not depend on whether the cloud is present in the daytime or at nighttime or on the concentration of $\mathrm{H}_{2} \mathrm{O}_{2}$ and $\mathrm{O}_{3}$, but is related to activation, supersaturation and the transition metal ion source and loading.

\subsection{Isotopic composition of $\mathrm{H}_{2} \mathrm{SO}_{4}$ gas and ultrafine particles}

The isotopic composition of sulfuric acid gas and ultrafine particulate reflects fractionation during removal and constrains the $\delta^{34} \mathrm{~S}$ value of the sulfate that can be added to particulate in the cloud by direct uptake processes (CON; DISS; SCAV and COAG; see Table 1). The upwind and downwind measurements of the isotopic composition of ultrafine sulfate particulate and sulfuric acid gas are shown in Fig. 4. A faulty sample meant no downwind isotopic composition could be measured for NCE 1 . The concentration of sulfuric acid gas was not measured during the campaign. Typical daytime sulfuric acid gas concentrations are $10^{6}-10^{7}$ molec $\mathrm{cm}^{-3}$ (Weber et al., 1997). Ultrafine particles

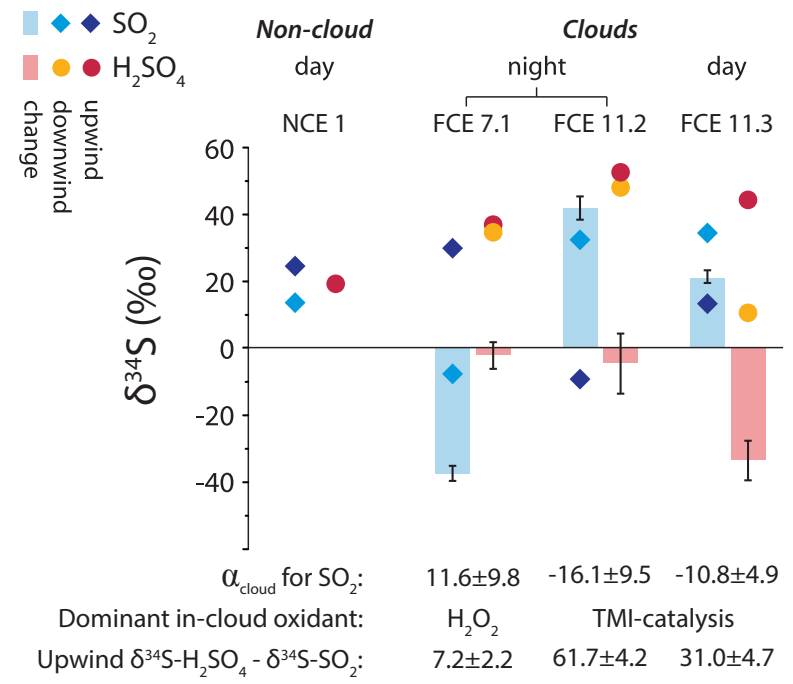

Fig. 4. Isotopic composition of $\mathrm{SO}_{2}$ (gas) and $\mathrm{H}_{2} \mathrm{SO}_{4}$ (gas + ultrafine particulate) upwind and downwind of orographic clouds during the HCCT-2010 campaign. Points show the upwind and downwind values of $\delta^{34} \mathrm{~S}$ while columns show the change (change $=\delta^{34} \mathrm{~S}_{\text {downwind }}-\delta^{34} \mathrm{~S}_{\text {upwind }}$ ) and the $1 \sigma$ error of the measurement.

with a diameter of $<50 \mathrm{~nm}$ are continuously present in the atmosphere (Kulmala et al., 2007). As the major atmospheric source of sulfuric acid gas is $\mathrm{SO}_{2}$ oxidation by $\mathrm{OH}$ radicals, the sulfuric acid gas concentration will be very low during the night-time events, so the sulfate measured during FCE 7.1 and 11.2 will primarily be due to ultrafine particles; the sulfate measured during FCE 11.3 will have a much greater contribution from $\mathrm{H}_{2} \mathrm{SO}_{4}$ gas.

The downwind $8^{34} \mathrm{~S}$ of $\mathrm{H}_{2} \mathrm{SO}_{4}$ gas and ultrafine sulfate particulate was lower than at the upwind station in the daytime cloud event, and the stations showed no significant difference during the two night-time events. No $\mathrm{OH}$ was measured in the daytime clouds or at night (Whalley et al., 2013), and only very low concentrations at the valley sites in the daytime, so the change in isotopic composition in the daytime event (FCE 11.3) is due to removal, rather than production, of gas-phase sulfuric acid and ultrafine particulate. The lack of isotopic discrimination during the night-time events (FCE 7.1 and FCE 11.2) is expected, as the $\mathrm{H}_{2} \mathrm{SO}_{4}$ (g)/ultrafine particulate sample is dominated by ultrafine particulate matter during the these two events: isotopic substitutions are too small relative to the particle mass to have any effect on physical processes. During the daytime event (FCE 11.3), the observed significant change in isotopic composition can therefore be attributed to the removal of gas-phase sulfuric acid, rather than the removal of ultrafine particulate.

Isotopic fractionation during $\mathrm{H}_{2} \mathrm{SO}_{4}$ removal in the cloud could be influenced both by diffusion (kinetic fractionation) and by equilibrium vapour pressure (equilibrium fractionation). The diffusion-dependent fractionation factor for gas-phase sulfuric acid is estimated from the ratio of 
$D_{\text {air }}\left(\mathrm{H}_{2}^{34} \mathrm{SO}_{4}\right)$ to $D_{\text {air }}\left(\mathrm{H}_{2}^{32} \mathrm{SO}_{4}\right)$, where $D_{\text {air }}$ is the diffusion coefficient in air, to be $\alpha_{\text {diff }}=0.995$. This is the opposite direction to the observed fractionation, showing that diffusion is not the limiting factor for loss. Vapour pressure is expected to cause fractionation in the opposite direction to diffusion: while the isotopic vapour pressure effect has not been measured for $\mathrm{H}_{2} \mathrm{SO}_{4}$, the vapour pressure for many analogous compounds is increased with a heavy isotope substitution - for example, deuterated methanol vapour pressure effects produce fractionation of 1.007 (Hopfner, 1969; Borowitz and Klein, 1971). $\mathrm{H}_{2} \mathrm{SO}_{4}(\mathrm{~g})$ uptake coefficients ranging from $\alpha=0.2$ to 0.8 (Jefferson et al., 1997) - depending on the amount of organic coating - have been reported in the literature. This corresponds to $\mathrm{H}_{2} \mathrm{SO}_{4}(\mathrm{~g})$ lifetimes ranging from a few minutes for the highest reported $\alpha$ values to approximately $20 \mathrm{~min}$ for $\alpha=0.2$. Even at the lower end of reported uptake coefficients, a significant fraction of the $\mathrm{H}_{2} \mathrm{SO}_{4}(\mathrm{~g})$ would be removed from the $\mathrm{H}_{2} \mathrm{SO}_{4}(\mathrm{~g}) /$ ultrafine particulate sample within the transit time through the cloud by $\mathrm{CON}$ and DISS, dominated by DISS due to the much larger surface area of cloud droplets than interstitial particles. The observed isotope fractionation in the $\mathrm{H}_{2} \mathrm{SO}_{4}(\mathrm{~g}) /$ ultrafine particulate sample in FCE 11.3 is consistent with $\mathrm{H}_{2} \mathrm{SO}_{4}$ (g) loss DISS controlled by the equilibrium vapour pressure above the solution (Henry's law solubility) and not by diffusion speed.

\subsection{Isotopic composition of $\mathrm{SO}_{2}$ gas compared to $\mathrm{H}_{2} \mathrm{SO}_{4}$ gas}

The upwind $\delta^{34} \mathrm{~S}$ of $\mathrm{H}_{2} \mathrm{SO}_{4}$ is higher than the $\delta^{34} \mathrm{~S}$ of $\mathrm{SO}_{2}$

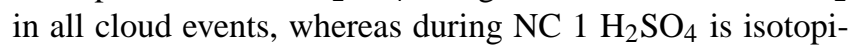
cally lighter than $\mathrm{SO}_{2}$ by $5.2 \pm 1.3 \%$. Evidence of air parcel mixing was seen in the $\mathrm{SO}_{2}$ isotopic composition for $\mathrm{NC} 1$ (Harris et al., 2013), thus the lighter $\mathrm{H}_{2} \mathrm{SO}_{4}$ compared to $\mathrm{SO}_{2}$ in $\mathrm{NC} 1$ can be attributed to recent mixing. The differences in the cloud events $\left(\delta^{34} \mathrm{~S}_{-} \mathrm{H}_{2} \mathrm{SO}_{4}-\delta^{34} \mathrm{~S}-\mathrm{SO}_{2}\right)$ are $7.2 \pm 2.2 \%$, $61.7 \pm 4.2 \%$ and $31.0 \pm 4.7 \%$ for FCE 7.1, 11.2 and 11.3 respectively. The fractionation factor for gas-phase production of sulfuric acid from oxidation of $\mathrm{SO}_{2}$ by $\mathrm{OH}$ radicals is $10.6 \pm 0.7 \%$ at $0^{\circ} \mathrm{C}$ (Harris et al., 2014), which agrees with the observed difference between the $\delta^{34} \mathrm{~S}_{\text {of }} \mathrm{SO}_{2}$ and $\mathrm{H}_{2} \mathrm{SO}_{4}$ for FCE 7.1. However, the known fractionation factor has a much smaller magnitude than the observed difference between the $\delta^{34} \mathrm{~S}$ of $\mathrm{SO}_{2}$ and $\mathrm{H}_{2} \mathrm{SO}_{4}$ for FCE 11.2 and 11.3. The only other known gas-phase production pathway for $\mathrm{H}_{2} \mathrm{SO}_{4}$ is $\mathrm{SO}_{2}$ oxidation by Criegee intermediates (Mauldin et al., 2012; Boy et al., 2013).

The difference between the observed $\delta^{34}{ }^{S}-\mathrm{H}_{2} \mathrm{SO}_{4}-\delta^{34} \mathrm{~S}$ $\mathrm{SO}_{2}$ and the expected difference from fractionation during gas-phase $\mathrm{SO}_{2}$ oxidation by $\mathrm{OH}$ radicals in FCE 11.2 and 11.3 could be due to a number of processes, such as contribution of Criegee radicals to oxidation, passage through clouds before the measurement site, or addition of fresh $\mathrm{SO}_{2}$ to the air mass shortly prior to reaching the sample site. Criegee radical oxidation is not expected to play an important role in sulfuric acid production during late autumn in temperature regions ( $<1 \%$; Pierce et al., 2013; Sarwar et al., 2013) and it is therefore very unlikely that the pathway played a significant role in the sulfur cycle during HCCT-2010. Air parcels in FCE 11.2 and 11.3 had recently passed through $\mathrm{SO}_{2}$ source regions (the "black triangle", see Fig. 1), unlike the FCE 7.1 air parcel. Isotopic composition of anthropogenic $\mathrm{SO}_{2}$ in these areas ranges from -5 to $10 \%$ o (Krouse et al., 1991; Jedrysek et al., 2002; Jezierski et al., 2006; Derda et al., 2007), thus it would reduce the $\delta^{34} S$ of $\mathrm{SO}_{2}$ from the expected values relative to ultrafine particulate and $\mathrm{H}_{2} \mathrm{SO}_{4}$ gas, resulting in the larger-than-expected observed differences between the two samples in FCE 11.2 and FCE 11.3, while in FCE 7.1 isotopic composition directly reflects sulfuric acid production and subsequent nucleation and growth.

\section{Isotopic composition of particulate sulfate}

Sulfate is added to particles as they pass through the cloud from a number of sources, described in Table 1. Sulfate addition at HCCT-2010 was also indicated by both offline and online measurements of chemical particle composition (D. van Pinxteren and L. Poulain, personal communication, 2014). Increased hygroscopicity - likely related to sulfate addition was observed with CCN measurements, as reported in a companion paper in this special issue (Henning et al., 2013). The change in the sulfur isotopic composition of particulate after passage through the cloud shows which sulfate sources dominate sulfate addition in the different particle classes. This is critical when estimating the effect of cloud processing on aerosol radiative forcing, as the sulfate sources and the sensitivity of radiative effects are not evenly distributed across all particles, as described in the introduction. A total of 128 particles, 54 from FCE 11.2 and 74 from FCE 11.3, were analysed to investigate the changes in isotopic composition between the measurement stations. At least five particles on each of the eight filters (upwind/downwind/interstitial/cloud droplet residual; coarse/fine) were analysed. Particles were chosen at random from the thousands of particles present on the filter, therefore there is no apparent bias and despite the small sample size inherent in this technique, the results are expected to be representative.

The $\delta^{34} \mathrm{~S}$ of the sulfate that could be added from each potential source was calculated from the upwind isotopic composition of $\mathrm{SO}_{2}$ or $\mathrm{H}_{2} \mathrm{SO}_{4}$ and the fractionation factors shown in Table 2. For $\mathrm{SO}_{2}$ removal, the fractionation factors for $\mathrm{SO}_{2}$ oxidation from Harris et al. (2012a, b) were used with the Rayleigh fractionation laws to account for depletion of the $\mathrm{SO}_{2}$ reservoir (Mariotti et al. (1981); Krouse and Grinenko (1991); fraction of $\mathrm{SO}_{2}$ oxidised determined in Harris et al., 2013). The $\delta^{34} \mathrm{~S}$ values of the sulfate that would be added by each source are shown in Table 4 and Fig. 5. These values will be compared to the isotopic changes observed in 
Table 4. $\delta^{34} \mathrm{~S}$ values $(\%$ ) of the potential sources of sulfate that could be contributed to particles during their passage through an orographic cloud: $\mathrm{SO}_{2}$ oxidation in the aqueous phase (AQOX) overall in the cloud $\left(\alpha_{\text {cloud }}\right)$, by $\mathrm{H}_{2} \mathrm{O}_{2}\left(\alpha_{\mathrm{H}_{2} \mathrm{O}_{2}}\right)$ and by transition metal catalysis $\left(\alpha_{\text {TMcat }}\right), \mathrm{SO}_{2}$ oxidation on the surface of Sahara dust with no aqueous phase (i.e. on interstitial particles, possibly involving $\mathrm{O}_{3}$ as described in Harris et al. (2012a); $\alpha_{\text {surf }}$ ), and direct uptake through DISS/SCAV of sulfuric acid gas and ultrafine particulate $\left(\alpha_{\text {dir }}\right)$.

\begin{tabular}{lrrr}
\hline Source & FCE 7.1 & FCE 11.2 & FCE 11.3 \\
\hline $\mathrm{SO}_{2}$ ox, $\alpha_{\text {cloud }}$ & $56.8 \pm 7.2$ & $-22.4 \pm 4.0$ & $5.6 \pm 2.1$ \\
$\mathrm{SO}_{2}$ ox, $\alpha_{\mathrm{H}_{2} \mathrm{O}_{2}}$ & $40.9 \pm 1.9$ & $1.5 \pm 3.2$ & $24.2 \pm 1.4$ \\
$\mathrm{SO}_{2}$ ox, $\alpha_{\mathrm{TMcat}}$ & $22.4 \pm 1.9$ & $-16.3 \pm 3.2$ & $6.0 \pm 1.4$ \\
$\mathrm{SO}_{2}$ ox, $\alpha_{\text {surf }}$ & $39.0 \pm 1.3$ & $-0.4 \pm 1.1$ & $22.3 \pm 1.1$ \\
$\mathrm{H}_{2} \mathrm{SO}_{4}, \alpha_{\text {dir }}$ & $37.3 \pm 5.0$ & $54.8 \pm 5.6$ & $44.8 \pm 4.5$ \\
\hline
\end{tabular}

the particulate sulfate in the following sections (Fig. 5), to determine the dominant process adding sulfate to each particle class and to estimate the amount of sulfate that must have been added to the particles to achieve isotope mass balance. The dominant processes for each particle class are summarised in Fig. 6.

The direction of change, rather than the absolute isotopic composition of downwind sulfate, allows the dominant sulfate source to be identified. For example, although the fine mineral dust in FCE 11.3 comes very close to the green line (oxidation by $\mathrm{H}_{2} \mathrm{O}_{2}$ ) following passage through the cloud, the direction of change shows us that direct sulfate uptake (pale blue line) dominates sulfate addition. The new sulfate mixes with the initial (upwind) sulfate, so if $\mathrm{H}_{2} \mathrm{O}_{2}$ oxidation of $\mathrm{SO}_{2}$ were the dominant process, the final (downwind) isotopic composition must fall between the initial composition and the green $\mathrm{H}_{2} \mathrm{O}_{2}$ oxidation line, not slightly above it. A summary of the major sulfate sources modifying each particle type is given in Table 5. A percentage increase in sulfate concentration is estimated. NanoSIMS measurements are surface-sensitive, thus for mineral dust and soot the percentage increase is an increase in surface sulfate only. Mixed particles will dissolve during cloud processing and reprecipitate when droplets evaporate after the cloud, thus the percentage increase for mixed particles is an increase in bulk sulfate.

\subsection{Mixed particles}

Mixed particles consist of secondary organic aerosol mixed with salt, and are the most numerous particles which take up significant sulfate in the cloud. Mixed particles and coated soot particles $>1 \mu \mathrm{m}$ in diameter were present only on the cloud droplet residual filters (i.e. those particles that were activated in the cloud, see Sect. 3.2); in the interstitial and at the valley sites these two types of particles were always $<1 \mu \mathrm{m}$ in size. Thus, size-resolved results are only presented

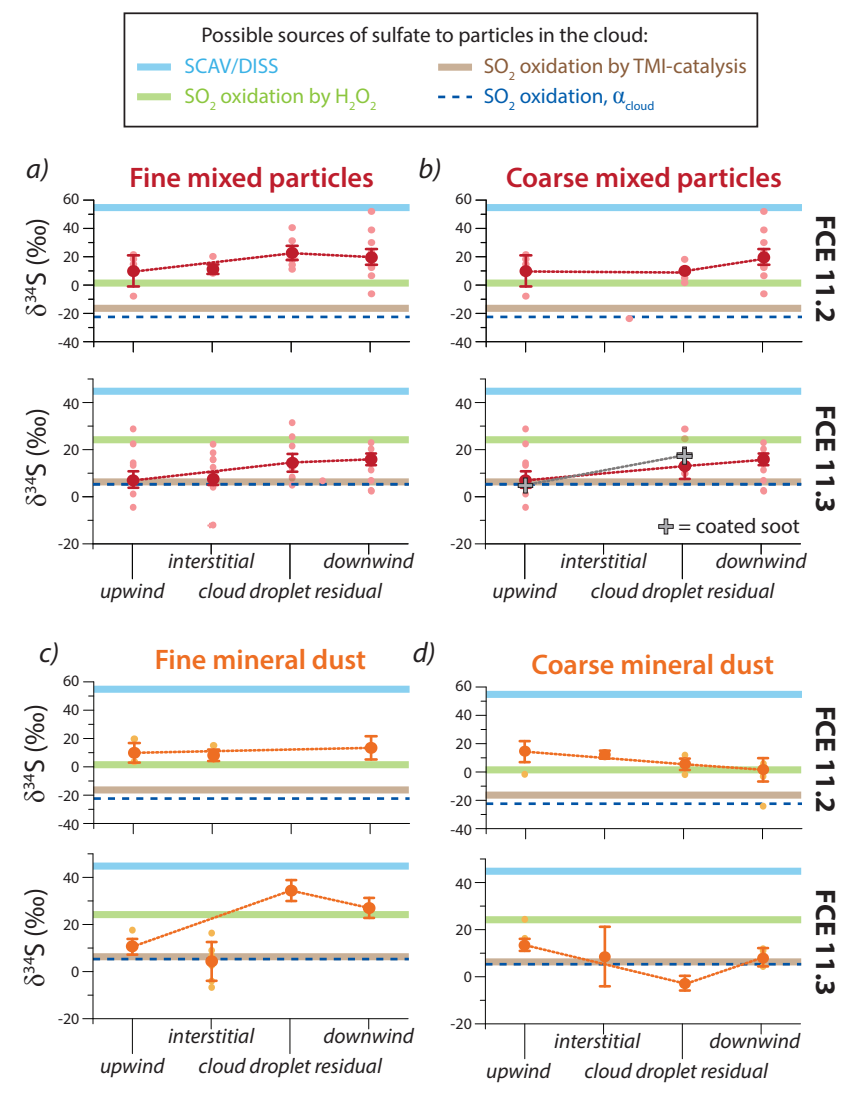

Fig. 5. Isotopic composition of particles measured during HCCT2010 for cloud events 11.2 and 11.3: (a) fine mixed particles (=OA + salt), (b) coarse mixed particles, (c) fine mineral dust, (d) coarse mineral dust. Mixed particles are shown in red and mineral dust in orange. Size-resolved mixed particles could only be measured in cloud droplet residual; upwind and downwind results are therefore equal for fine and coarse particles. In (b) for FCE 11.3 sulfur was also measured in coated soot particles, shown as grey crosses. Straight thick lines (blue, green and brown) show the isotopic composition of sulfate that could be added to particles in the cloud from different sources according to the legend, and the dashed dark blue line shows the sulfate that would have been added from the $\mathrm{SO}_{2}$ removal $\left(\alpha_{\text {cloud }}\right)$ as discussed in Harris et al. (2013) (values given in Table 4). Pale circles show measurements for individual grains and larger, dark circles with error bars show the mean and the $1 \sigma$ error. Dotted lines follow from upwind to in-cloud to downwind particles and show the change in $\delta^{34} \mathrm{~S}$ due to cloud processing.

for cloud droplet residual particles (Fig. 5a and b). The $\delta^{34} \mathrm{~S}$ of mixed particles increased as the particles passed through the cloud in both FCE 11.2 and 11.3. The increase in $\delta^{34} \mathrm{~S}$ was significantly greater for fine than coarse mixed particles during FCE 11.2, and slightly greater for fine mixed particles during FCE 11.3. AMS results showed that the upwind sulfate mass fraction in the particulate was not significantly different depending on size (L. Poulain, personal communication, 2014). 
Table 5. Dominant sulfate sources to different particle classes observed with sulfur isotope analyses at HCCT-2010: $\mathrm{H}_{2} \mathrm{O}_{2}$ and TMI-cat refer to in situ oxidation of $\mathrm{SO}_{2}$ (AQOX). Percentage increases in sulfate concentration are approximate, and refer to surface sulfate for mineral dust and bulk sulfate for mixed particles and coated soot. "Coarse" and "fine" refer to particle size ranges of approximately $>600 \mathrm{~nm}$ and 50-600 nm respectively (see Sect. 3.2).

\begin{tabular}{llll|l|ll}
\hline & & \multicolumn{2}{c|}{ Mixed particles } & Coated soot & \multicolumn{2}{c}{ Mineral dust } \\
\cline { 3 - 7 } & & Fine & Coarse & Coarse & Fine & Coarse \\
\hline \multirow{2}{*}{ FCE 11.2} & \% Addition & $>40$ & 10 & Not measured & Not activated & $>40$ \\
& Dominant process & SCAV/DISS & $\mathrm{H}_{2} \mathrm{O}_{2}$ & & & TMI-cat \\
FCE 11.3 & \% Addition & $23-72$ & $25-100$ & $47-190$ & $>200$ & $>40$ \\
& Dominant process & SCAV/DISS/ $\mathrm{H}_{2} \mathrm{O}_{2}$ & $\mathrm{H}_{2} \mathrm{O}_{2}$ & $\mathrm{H}_{2} \mathrm{O}_{2}$ & SCAV/DISS & TMI-cat \\
\hline
\end{tabular}

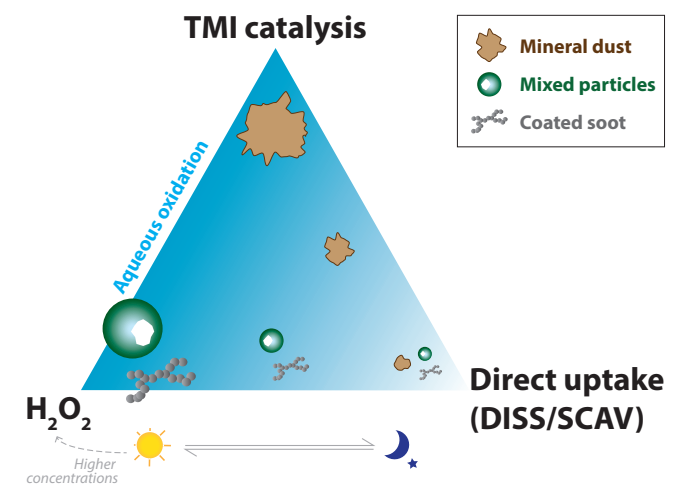

Fig. 6. Schematic summary of the dominant processes contributing sulfate to different particle classes during cloud processing at HCCT-2010. Particle size ranges are (approximately) fine, $<600 \mathrm{~nm}$, and coarse, $>1 \mu \mathrm{m}$.

The only sulfate source that could enrich fine mixed particles in ${ }^{34} \mathrm{~S}$ during FCE 11.2 is direct uptake through DISS and SCAV (pale blue line); the latter will dominate as the event is at night-time, so the gas-phase sulfuric acid concentration will be very low (Weber et al., 1997). If this is the only source of sulfate for the particles, the sulfate concentration must increase by $40 \%$ to account for the change in isotopic composition. This represents a minimum sulfate addition as any other sulfate sources would change the isotopic composition in the opposite direction, requiring a larger addition from direct uptake. During FCE 11.3 the increase in $\delta^{34} \mathrm{~S}$ of fine mixed particles could be due to either DISS/SCAV or AQOX by $\mathrm{H}_{2} \mathrm{O}_{2}$ (pale blue and green lines respectively). Sulfate on mixed particles increased by between 23 and $72 \%$ in this event. The concentration of $\mathrm{H}_{2} \mathrm{O}_{2}$ measured during FCE 11.3 was much higher than during FCE 11.2 (7.4 and 2.9 $\mu \mathrm{M}$ in cloud water respectively), explaining why sulfate addition from $\mathrm{H}_{2} \mathrm{O}_{2}$ oxidation of $\mathrm{SO}_{2}$ (g) is more important during FCE 11.3 than FCE $11.2 . \mathrm{H}_{2} \mathrm{O}_{2}$ concentration is consistently higher in the daytime due to the photochemical production of OH (Kanaya et al., 2007; Gnauk et al., 1997), so it is likely that oxidation by $\mathrm{H}_{2} \mathrm{O}_{2}$ by $\mathrm{SO}_{2}$ is generally more important in the daytime, as observed at HCCT-2010.
Mixed particles on the coarse filter become more isotopically variable as they pass through the cloud in FCE 11.2, and isotopically heavier in FCE 11.3 (Fig. 5b). For FCE 11.2 this suggests sulfate addition by both DISS/SCAV and from AQOX by $\mathrm{H}_{2} \mathrm{O}_{2}$; while for FCE 11.3 , oxidation of $\mathrm{SO}_{2}$ by $\mathrm{H}_{2} \mathrm{O}_{2}$ is the dominant sulfate addition source. Sulfate increases by approximately $10 \%$ and $100 \%$ in FCE 11.2 and 11.3 respectively, although for FCE 11.2 this value is quite uncertain. For FCE 11.3 the addition could be lower if some sulfate was also added from DISS/SCAV (as low as $25 \%$ if all sulfate is from DISS/SCAV).

Overall, AQOX by $\mathrm{H}_{2} \mathrm{O}_{2}$ is more important in mixed particles in the daytime due to higher $\mathrm{H}_{2} \mathrm{O}_{2}$ concentrations (Kanaya et al., 2007; Gnauk et al., 1997), but there is also variation due to particle size: DISS/SCAV are relatively more important for adding sulfate to smaller mixed particles, while for larger mixed particles AQOX by $\mathrm{H}_{2} \mathrm{O}_{2}$ is relatively more important, as summarised in Fig. 6. Modification of fine particles has a stronger effect on the magnitude of direct and indirect aerosol forcing, thus for night-time cloud processing, direct sulfate uptake through DISS/SCAV may play a more important role than aqueous $\mathrm{SO}_{2}$ oxidation in controlling the effect of sulfate on climate. During the daytime, both processes will contribute depending on factors such as insolation, air mass history and oxidant concentrations.

Comparing the cloud droplet residual and interstitial values with the downwind $\delta^{34} \mathrm{~S}$ can provide an estimate of (i) sulfate addition to the interstitial particles during passage through the cloud, and (ii) the proportion of sulfur in the interstitial phase compared to $\mathrm{CCN}$-active particles. Sulfate can be added to interstitial particles from surface oxidation reactions, and from condensing and coagulating sulfuric acid and ultrafine particulate (CON and COAG). Sulfate addition from these pathways would significantly alter the isotopic composition of the interstitial particles. This was not observed at HCCT, hence sulfate mass addition to interstitial particles during passage through the cloud appears to be minor. The isotopic compositions in-cloud and downwind are not significantly different for the daytime or the night-time event, whereas the interstitial $\delta^{34} \mathrm{~S}$ is lower, thus very little mixed particle sulfur was present in the interstitial phase. 
This shows efficient activation of sulfate-containing mixed particles, consistent with the results from SEM analysis and with AMS results (Sinha et al., 2014a; Harris et al., 2013).

\subsection{Coated soot}

In FCE 11.2, SEM results showed that the majority of coated soot remained in the interstitial phase, while in FCE 11.3 coated soot was activated and gained sulfate through processing. Activation to cloud droplets depended on the amount of soluble material (coating) associated with the soot (Sinha et al., 2014a). In FCE 11.3 it appears that $\mathrm{CON}$ of $\mathrm{H}_{2} \mathrm{SO}_{4}$ (g) during the daytime increases the hygroscopicity of the coated soot particles, facilitating activation and further incloud sulfate addition through AQOX by $\mathrm{H}_{2} \mathrm{O}_{2}$. Similar behaviour was seen for fine mineral dust, discussed in the following section. The change in $\delta^{34} \mathrm{~S}$ of coated soot during FCE 11.3 shows that the surface sulfate was increased by between 47 and $190 \%$ (if in-cloud sulfate production was solely from DISS/SCAV or from AQOX by $\mathrm{H}_{2} \mathrm{O}_{2}$, respectively). The change is not significantly different to what was seen in mixed particles. This is expected: following activation, the coating will dissolve and the cloud droplet will behave similarly to a cloud droplet formed on a SOA/SIA mixed droplet with no soot particle. The soot core itself does not appear to influence cloud processing.

\subsection{Mineral dust}

The decrease in $\delta^{34} \mathrm{~S}$ downwind as interstitial and cloud droplet residual particles are re-mixed shows that $\sim 70 \%$ of the sulfur in fine mineral dust is activated in FCE 11.3; in contrast, no fine mineral dust sulfur was activated during FCE 11.2. SEM analyses agree well with NanoSIMS results: during FCE 11.3, SEM analysis showed that 70-80\% of mineral dust particles in the $400-1000 \mathrm{~nm}$ size range acted as a cloud condensation nucleus (Sinha et al., 2014a). During FCE 11.2, no mineral dust was found with the SEM on the cloud droplet residual fine filter, so it is likely that fine mineral dust was unable to act as a cloud condensation nucleus, despite particle diameters as large as $600 \mathrm{~nm}$, due to its hydrophobic nature (Kaaden et al., 2009). In all fine mineral dust in FCE 11.2 and between the upwind and interstitial in FCE 11.3, there is no significant change in $\delta^{34} \mathrm{~S}$ (Fig. 5c), thus no significant sulfate is added to fine mineral dust as it passes through the cloud as interstitial aerosol.

In contrast, there is a large change in the $\delta^{34} S$ of sulfate in cloud droplet residual and downwind fine mineral dust in the daytime event FCE 11.3 (Fig. 5c). The fine dust was able to act as $\mathrm{CCN}$ in this event, possibly because higher daytime $\mathrm{H}_{2} \mathrm{SO}_{4}$ concentrations increased the hygroscopicity through CON (and COAG) prior to the cloud - similarly to coated soot in FCE 11.3. The in-cloud change to such high $\delta^{34} \mathrm{~S}$ values shows the importance of DISS/SCAV for in-cloud sulfate addition to fine mineral dust (pale blue line). The surface sulfate in these particles increased by $>200 \% . \mathrm{H}_{2} \mathrm{SO}_{4}(\mathrm{~g})$ concentration is much higher in the daytime than at night because it is produced by $\mathrm{OH}$ radicals. Higher sulfuric acid concentrations in the daytime leads to sulfate addition on to fine mineral dust, increasing its hygroscopicity; this in turn increases its $\mathrm{CCN}$ activity, facilitating further uptake of $\mathrm{H}_{2} \mathrm{SO}_{4}$ (g) due to the higher surface area of a cloud droplet compared to the surface area of the particle serving as $\mathrm{CCN}$.

During both FCE 11.2 and 11.3 the $\delta^{34} \mathrm{~S}$ of mineral dust on the coarse filter decreases as it passes through the cloud, by $-8.9 \pm 8.5 \%$ and $-16.3 \pm 4.0 \%$ respectively (Fig. $5 \mathrm{~d}$ ). This can only be accounted for by sulfate addition from AQOX by transition metal catalysis; oxidation by $\mathrm{H}_{2} \mathrm{O}_{2}$ in FCE 11.2 would require an increase in sulfate of $>400 \%$ and in FCE 11.3 no other source could add such isotopically light sulfate. AQOX by transition metal catalysis increases the surface sulfate on the coarse mineral dust particles by $>40 \%$ in both events. Considering both the number of particles found as droplet residue and on the interstitial filters, and the downwind isotopic composition, in both events the majority of sulfate addition to coarse mode mineral dust takes place inside cloud droplets and not in the interstitial phase. Coarse mineral dust is the only particle type where sulfate addition introduces an isotopic fractionation consistent with the major $\mathrm{SO}_{2}$ removal process, i.e. causing the residual $\mathrm{SO}_{2}$ to be enriched in ${ }^{34} \mathrm{~S}$. Thus, oxidation by the transition metal ion catalysis pathway in cloud droplets formed on coarse mineral dust particles dominates $\mathrm{SO}_{2}$ uptake and oxidation in the measured events.

\section{Conclusions}

The sulfur cycle observed during the HCCT-2010 campaign was complex, with different reactions responsible for adding sulfate to the different classes of particulate as they passed through the cloud (Fig. 6 and Table 5). Sulfate addition was also indicated in clouds at HCCT-2010 through online and offline chemical composition measurements (D. van Pinxteren and L. Poulain, personal communication, 2014), and indirectly observed as an increase in hygroscopicity following in-cloud processing (Henning et al., 2013). No significant modification of interstitial particles was seen at HCCT-2010. Fine and coarse mixed particles showed a shift in the dominant sulfate source added in the cloud from dissolution of $\mathrm{H}_{2} \mathrm{SO}_{4}$ and scavenging of ultrafine particulate to aqueous oxidation by $\mathrm{H}_{2} \mathrm{O}_{2}$ with increasing particle size. In the daytime $\mathrm{H}_{2} \mathrm{O}_{2}$ oxidation was overall more important than at night due to higher daytime $\mathrm{H}_{2} \mathrm{O}_{2}$ concentrations (Fig. 6). The same behaviour was seen in coarse coated soot particles in FCE 11.3.

Fine mineral dust particles were able to act as $\mathrm{CCN}$ in the daytime as they had taken up $\mathrm{H}_{2} \mathrm{SO}_{4}(\mathrm{~g})$ before the cloud through condensation. As they passed through the cloud the increased surface area following activation led to further 
$\mathrm{H}_{2} \mathrm{SO}_{4}(\mathrm{~g})$ and ultrafine particulate uptake, increasing hygroscopicity and thus facilitating $\mathrm{CCN}$ activity in subsequent clouds. At night fine mineral dust particles were unable to act as $\mathrm{CCN}$ due to low $\mathrm{H}_{2} \mathrm{SO}_{4}$ production, therefore they did not activate and significant sulfate was not added between the upwind and downwind stations. Although the surface sulfur in activated mixed particles, coated soot and fine mineral dust increased by 40 to $>200 \%$ as they passed through the cloud, the direction of the observed isotopic changes meant that none of these particle classes could account for the dominant loss of $\mathrm{SO}_{2}(\mathrm{~g})$. In contrast, coarse mineral dust became enriched in ${ }^{32} \mathrm{~S}$ as it passed through the cloud, consistent with isotope fractionation during $\mathrm{SO}_{2}$ removal. Transition metal ions from mineral dust leachate cause very fast oxidation of $\mathrm{SO}_{2}$ (Tilly et al., 1991; Rani et al., 1992; Harris et al., 2012a), and the efficiency of oxidation by this pathway means that, despite the relatively low number concentration of these particles compared to, for example, mixed particles, they are able to account for the majority of in-cloud $\mathrm{SO}_{2}$ oxidation at Schmücke (discussed further in Harris et al. (2013).

The results of this study have important implications for the role of in-cloud sulfate production in modifying of the aerosol size distribution. When $\mathrm{H}_{2} \mathrm{O}_{2}$ is the dominant oxidant for $\mathrm{SO}_{2}$, sulfate mass from $\mathrm{SO}_{2}$ oxidation is modelled to be added early in the cloud, as $\mathrm{H}_{2} \mathrm{O}_{2}$ is quickly exhausted (Bower and Choularton, 1993; Bower et al., 1997). This means the sulfate mass is added primarily to the most CCNactive particles which are activated earliest in the cloud, and a high degree of supersaturation is needed early in the cloud to have a significant effect on the smallest, least efficient CCN (Bower et al., 1997). In contrast, transition metalcatalysed oxidation will proceed throughout the cloud, consistent with the observed $\mathrm{SO}_{2}$ concentrations (Harris et al., 2013). Thus, $\mathrm{SO}_{2}$ oxidation is able to add sulfate mass to particles throughout the cloud: it is not only important for those particles activated earliest in the cloud.

The particulate isotope measurements show, however, that direct sulfate uptake through dissolution of $\mathrm{H}_{2} \mathrm{SO}_{4}$ gas and scavenging of ultrafine particulate is the dominant process, adding sulfate mass to the smallest and least hygroscopic $\mathrm{CCN}$ - fine mineral dust and fine mixed particles - at night, and of similar importance to aqueous oxidation of $\mathrm{SO}_{2}$ in the daytime. Therefore, at night direct sulfate uptake is likely to be the most important in-cloud sulfate addition process for modifying $\mathrm{CCN}$ activity, and thus determining the strength of the indirect aerosol effect. In the daytime, increased $\mathrm{H}_{2} \mathrm{O}_{2}$ concentrations mean that both pathways will be important for modifying the smallest particles. Both processes can be important in affecting the magnitude of direct aerosol cooling, where modifications have a significant effect also for larger CCN particles.

The results demonstrate the potential of sulfur isotope measurements for investigating $\mathrm{SO}_{2}$ oxidation, particularly when single-particle isotope ratios are measured with NanoSIMS. The application of this technique to other sys- tems, for example the formation of nitrate and other nitrogen compounds in clouds, may show similar behaviour to the sulfate system and be an ideal topic for NanoSIMS investigation. Organic matter production in clouds accounts for a large amount of mass gain. A NanoSIMS study of OA formation could yield exciting results although it may be challenging compared to the simpler sulfate case. Investigatory studies looking at the variation in carbon isotopic composition between characteristic SOA types or important precursor compounds, as well as a study of the behaviour, matrix effects and precision of ${ }^{13} \mathrm{C}$ measurements in aerosol particles with NanoSIMS, would provide an idea of the feasibility of a study of this type.

Incorporating the findings of this study into models will result in a much more accurate depiction of the continental sulfur cycle and the effect of cloud processing on the environmental effect of $\mathrm{SO}_{2}$ and sulfate. However, it is not currently feasible to mechanistically capture extremely detailed single-particle results, such as those obtained in this study, into full-scale global climate models - although a number of recent studies have successfully applied particle-resolved models to investigate black carbon on a local and regional scale (Riemer et al., 2009; Kajino and Kondo, 2011; Ching et al., 2012). The findings of this study which are most likely to have a large impact on modelled sulfate distributions and associated radiative forcing are (i) the importance of the TMI catalysis pathway, particularly in creating sulfate that may be quickly removed from the atmosphere on large particles, and (ii) the large impact direct sulfate uptake may have on the smallest particles, even when it is not the most important process on a total mass basis. These effects will be most important in environments such as Asia, where $\mathrm{SO}_{2}$ and dust concentrations may be very high, and in areas where water vapour concentrations are higher so that clouds are more sensitive to increases in $\mathrm{CCN}$ number concentration. Under these two cases, we would expect that models in which sulfate addition is not resolved for particle type may overestimate and underestimate the cooling effect and lifetime of sulfate aerosol respectively. Future model studies considering the potential role of these processes first on a smaller scale, as in the black carbon case, and then on a regional scale in sensitive areas, will help to parametrise these effects to improve modelling of $\mathrm{SO}_{2}$ and sulfate in global-scale studies.

Acknowledgements. We thank Elmar Gröner for his support with the NanoSIMS analyses, Joachim Huth for his help with the SEM/EDX analyses, and all the participants of HCCT-2010 for an interesting and successful campaign. This research was funded by the Max Planck Society and the Max Planck Graduate Centre. The HCCT-2010 campaign was partially funded by the Deutsche Foschungsgemeinschaft under contract HE 3086/15-1 and grant ME 3534/1-2. Participation of the Colorado State University scientists was supported by grants from TROPOS Leipzig and by NSF grant AGS 1050052. 
The service charges for this open access publication have been covered by the Max Planck Society.

Edited by: M. C. Facchini

\section{References}

Alexander, B., Park, R. J., Jacob, D. J., and Gong, S. L.: Transition metal-catalyzed oxidation of atmospheric sulfur: Global implications for the sulfur budget, J. Geophys. Res.-Atmos., 114, D02309, doi:10.1029/2008JD010486, 2009.

Bevington, P. and Robinson, D.: Data Reduction and Error Analysis for the Physical Sciences, Mc-Graw Hill, 1992.

Borowitz, J. and Klein, F.: Vapor Pressure Isotope Effects in Methanol, The J. Phys. Chem., 75, 1815-1820, 1971.

Boucher, O. and Lohmann, U.: The sulfate-CCN-cloud albedo effect: A sensitivity study with two general circulation models, Tellus B, 47, 281-300, 1995.

Bower, K. N. and Choularton, T. W.: Cloud processing of the Cloud Condensation Nucleus spectrum and its climatological consequences, Q. J. Roy. Meteor. Soc., 119, 655-679, 1993.

Bower, K. N., Choularton, T. W., Gallagher, M. W., Colvile, R. N., Wells, M., Beswick, K. M., Wiedensohler, A., Hansson, H. C., Svenningsson, B., Swietlicki, E., Wendisch, M., Berner, A., Kruisz, C., Laj, P., Facchini, M. C., Fuzzi, S., Bizjak, M., Dollard, G., Jones, B., Acker, K., Wieprecht, W., Preiss, M., Sutton, M. A., Hargreaves, K. J., StoretonWest, R. L., Cape, J. N., and Arends, B. G.: Observations and modelling of the processing of aerosol by a hill cap cloud, Atmos. Environ., 31, 2527-2543, 1997.

Boy, M., Mogensen, D., Smolander, S., Zhou, L., Nieminen, T., Paasonen, P., Plass-Dülmer, C., Sipilä, M., Petäjä, T., Mauldin, L., Berresheim, H., and Kulmala, M.: Oxidation of $\mathrm{SO}_{2}$ by stabilized Criegee intermediate $(\mathrm{sCI})$ radicals as a crucial source for atmospheric sulfuric acid concentrations, Atmos. Chem. Phys., 13, 3865-3879, doi:10.5194/acp-13-3865-2013, 2013.

Bradbury, C., Bower, K. N., Choularton, T. W., Swietlicki, E., Birmili, W., Wiedensohler, A., Yuskiewicz, B. A., Berner, A., Dusek, U., Dore, C., and Mcfadyen, G.: Modelling of aerosol modification resulting from passage through a hill cap cloud, Atmos. Res., 50, 185-204, 1999.

Brueggemann, E., Gnauk, T., Mertes, S., Acker, K., Auel, R., Wieprecht, W., Moeller, D., Collett, J., Chang, H., Galgon, D., Chemnitzer, R., Rued, C., Junek, R., Wiedensohler, A., and Herrmann, H.: Schmuecke hill cap cloud and valley stations aerosol charaterisation during FEBUKO (I): Particle size distribution, mass, and main components, Atmos. Environ., 39, 4291-4303, 2005.

CEIP: Sulfur dioxide emission data, http://www.ceip.at/ceip, 2010.

Ching, J., Riemer, N., and West, M.: Impact of black carbon mixing state on black carbon nucleation scavenging: Insights from a particle-resolved models, J. Geophys. Res.-Atmos., 117, D23209, doi:10.1029/2012JD018269, 2012.

Cohen, S., Chang, S. G., Markowitz, S. S., and Novakov, T.: Role of fly ash in catalytic oxidation of sulfur(IV) slurries, Environ. Sci. Technol., 15, 1498-1502, doi:10.1021/es00094a013, 1981.

Derda, M., Chmielewski, A. G., and Licki, J.: Sulphur isotope compositions of components of coal and S-isotope fractionation dur- ing its combustion and flue gas desulphurization, Isot. Environ. Healt. S., 43, 57-63, 2007.

Ding, T., Valkiers, S., Kipphardt, H., De Bievre, P., Taylor, P. D. P., Gonfiantini, R., and Krouse, R.: Calibrated sulfur isotope abundance ratios of three IAEA sulfur isotope reference materials and V-CDT with a reassessment of the atomic weight of sulfur, Geochim. Cosmochim. Ac., 65, 2433-2437, 2001.

Flynn, M., Bower, K. N., Choularton, T. W., Wobrock, W., J.M., M., Martinsson, B., Frank, G., Hannsson, H.-C., Karlsson, H., and Laj, P.: Modelling cloud processing of aerosol during the ACE-2 HILLCLOUD experiment, Tellus B, 52, 779-800, 2000.

Gnauk, T., Rolle, W., and Spindler, G.: Diurnal variations of atmospheric hydrogen peroxide concentrations in Saxony (Germany), J. Atmos. Chem., 27, 79-103, 1997.

Groener, E. and Hoppe, P.: Automated ion imaging with the NanoSIMS ion microprobe, Appl. Surf. Sci., 252, 7148-7151, doi:10.1016/j.apsusc.2006.02.280, 2006.

Harris, E., Sinha, B., Foley, S., Crowley, J. N., Borrmann, S., and Hoppe, P.: Sulfur isotope fractionation during heterogeneous oxidation of $\mathrm{SO}_{2}$ on mineral dust, Atmos. Chem. Phys., 12, 48674884, doi:10.5194/acp-12-4867-2012, 2012a.

Harris, E., Sinha, B., Hoppe, P., Crowley, J. N., Ono, S., and Foley, S.: Sulfur isotope fractionation during oxidation of sulfur dioxide: gas-phase oxidation by $\mathrm{OH}$ radicals and aqueous oxidation by $\mathrm{H}_{2} \mathrm{O}_{2}, \mathrm{O}_{3}$ and iron catalysis, Atmos. Chem. Phys., 12, 407423, doi:10.5194/acp-12-407-2012, 2012.

Harris, E., Sinha, B., van Pinxteren, D., Tilgner, A., Fomba, W., Schneider, J., Roth, A., Gnauk, T., Fahlbusch, B., Mertes, S., Lee, T., Collett, J., Foley, S., Borrmann, S., Hoppe, P., and Herrmann, H.: Enhanced role of transition metal ion catalysis during in-cloud oxidation of $\mathrm{SO}_{2}$, Science, 340, 727-730, doi:10.1126/science.1230911, 2013.

Harris, E., Sinha, B., Hoppe, P., and Ono, S.: High-precision measurements of $33 \mathrm{~S}$ and $34 \mathrm{~S}$ fractionation during $\mathrm{SO}_{2}$ oxidation reveal causes of seasonality in $\mathrm{SO}_{2}$ and sulfate isotopic composition, Environ. Sci. Technol., 47, 12174-12183, doi:10.1021/es402824c, 2014.

Hegg, D.: Cloud condensation nucleus-sulfate mass relationship and cloud albedo, J. Geophys. Res., 99, 25903-25907, 1994.

Hegg, D. A., Covert, D. S., Jonsson, H., Khelif, D., and Friehe, C. A.: Observations of the impact of cloud processing on aerosol light-scattering efficiency, Tellus B, 56, 285-293, 2004.

Henning, S., Dieckmann, K., Ignatius, K., Schäfer, M., Zedler, P., Harris, E., Sinha, B., van Pinxteren, D., Mertes, S., Birmili, W., Merkel, M., Wu, Z., Wiedensohler, A., Wex, H., Herrmann, H., and Stratmann, F.: Influence of cloud processing on CCN activation behaviour in the Thuringian Forest, Germany during HCCT-2010, Atmos. Chem. Phys. Discuss., 14, 1617-1645, doi:10.5194/acpd-14-1617-2014, 2014.

Hopfner, A.: Vapor Pressure Isotope Effects, Angew. Chem. Int. Edit., 8, 689-699, doi:10.1002/anie.196906891, 1969.

Hoppe, P.: NanoSIMS: A new tool in cosmochemistry, Appl. Surf. Sci., 252, 7102-7106, 2006.

Hoppel, W., Frick, G., Fitzgerald, J., and Wattle, B.: A cloud chamber study of the effect that nonprecipitating clouds have on the aerosol size distribution, Aerosol Sci. Tech., 20, 1-30, 1994.

Hoppel, W. A., Frick, G. M., and Larson, R. E.: Effect of Nonprecipitating Clouds On the Aerosol Size Distribution In the 
Marine Boundary-layer, Geophys. Res. Lett., 13, 125-128, doi:10.1029/GL013i002p00125, 1986.

Ibusuki, T. and Takeuchi, K.: Sulfur dioxide oxidation by oxygen catalyzed by mixtures of manganese(II) and iron(III) in aqueous solutions at environmental reaction conditions, Atmos. Environ., 21, 1555-1560, 1987.

IPCC: Climate Change 2013 - The Physical Science Basis: Working Group I Contribution to the Fifth Assessment Report of the Intergovernmental Panel on Climate Change, Cambridge University Press, 2013.

Jedrysek, M. O., Kaluzny, A., and Hoefs, J.: Sulphur and oxygen isotope ratios in spruce needles as a tracer of atmospheric pollution, J. Geophys. Res.-Atmos., 107, 4353, doi:10.1029/2001JD000527, 2002.

Jefferson, A., Eisele, F. L., Ziemann, P. J., Weber, R. J., Marti, J. J., and McMurry, P. H.: Measurements of the H2SO4 mass accommodation coefficient onto polydisperse aerosol, J. Geophys. Res.-Atmos., 102, 19021-19028, doi:10.1029/97JD01152, 1997.

Jezierski, P., Szynkiewicz, A., and Jedrysek, M. O.: Natural and anthropogenic origin sulphate in an mountainous groundwater system: S and O isotope evidences, Water Air Soil Pollut., 173, 81-101, doi:10.1007/s11270-005-9028-3, 2006.

Jickells, T. D., An, Z. S., Andersen, K. K., Baker, A. R., Bergametti, G., Brooks, N., Cao, J. J., Boyd, P. W., Duce, R. A., Hunter, K. A., Kawahata, H., Kubilay, N., laRoche, J., Liss, P. S., Mahowald, N., Prospero, J. M., Ridgwell, A. J., Tegen, I., and Torres, R.: Global iron connections between desert dust, ocean biogeochemistry, and climate, Science, 308, 67-71, doi:10.1126/science.1105959, 2005.

John, W., Hering, S., Reischl, G., Sasaki, G., and Goren, S.: Characteristics of Nuclepore Filters With Large Pore-size. 2. Filtration Properties, Atmos. Environ., 17, 373-382, doi:10.1016/00046981(83)90054-9, 1983

Jones, A., Roberts, D., and Slingo, A.: A climate model study of indirect radiation forcing by anthropogenic sulphate aerosols, Nature, 370, 450-453, 1994.

Kaaden, N., Massling, A., Schladitz, A., Mueller, T., Kandler, K., Schuetz, L., Weinzierl, B., Petzold, A., Tesche, M., Leinert, S., Deutscher, C., Ebert, M., Weinbruch, S., and Wiedensohler, A.: State of mixing, shape factor, number size distribution, and hygroscopic growth of the Saharan anthropogenic and mineral dust aerosol at Tinfou, Morocco, Tellus B, 61, 51-63, doi:10.1111/j.1600-0889.2008.00388.x, 2009.

Kajino, M. and Kondo, Y.: EMTACS: Development and regionalscale simulation of a size, chemical, mixing type, and soot shape resolved atmospheric particle model, J. Geophys. Res.-Atmos., 116, D02303, doi:10.1029/2010JD015030, 2011.

Kanaya, Y., Tanimoto, H., Matsumoto, J., Furutani, H., Hashimoto, S., Komazaki, Y., Tanaka, S., Yokouchi, Y., Kato, S., Kajii, Y., and Akimoto, $\mathrm{H}$.: Diurnal variations in $\mathrm{H}_{2} \mathrm{O}_{2}, \mathrm{O}_{3}, \mathrm{PAN}, \mathrm{HNO}_{3}$ and aldehyde concentrations and $\mathrm{NO} / \mathrm{NO}_{2}$ ratios at Rishiri Island, Japan: Potential influence from iodine chemistry, Sci. Total Environ., 376, 185-197, doi:10.1016/j.scitotenv.2007.01.073, 2007.

Kasper-Giebl, A., Koch, A., Hitzenberger, R., and Puxbaum, H.: Scavenging efficiency of "aerosol carbon" and sulfate in supercooled clouds at Mt. Sonnblick (3106 m a.s.l., Austria), J. Atmos. Chem., 35, 33-46, 2000.
Kreidenweis, S. M., Walcek, C. J., Feingold, G., Wanmin, G., Jacobson, M. Z., Cheol-Hee, K., Xiaohong, L., Penner, J. E., Nenes, A., and Seinfeld, J. H.: Modification of aerosol mass and size distribution due to aqueous-phase $\mathrm{SO}_{2}$ oxidation in clouds: Comparisons of several models, J. Geophys. Res., 108, D74213, doi:10.1029/2002JD002697, 2003.

Krouse, H., Grinenko, L., Grinenko, V., Newman, L., Forrest, J., Nakai, N., Tsuji, Y., Yatsumimi, T., Takeuchi, V., Robinson, B., Stewart, M., Gunatilaka, A., Plumb, L., Smith, J., Buzek, F., Cerny, J., Sramek, J., Menon, A., Iyer, G., Venkatasubramanian, V., Egboka, B., Irogbenachi, M., and Eligwe, C.: Stable Isotopes: Natural and Anthropogenic Sulphur in the Environment, chap. 8. Case Studies and Potential Applications, 307-416, Wiley, Chichester, 1991.

Krouse, H. R. and Grinenko, V. A.: Stable isotopes: Natural and anthropogenic sulphur in the environments, Vol. 43, Wiley, Chichester, 1991.

Kulmala, M., Riipinen, I., Sipila, M., Manninen, H. E., Petaja, T., Junninen, H., Maso, M. D., Mordas, G., Mirme, A., Vana, M., Hirsikko, A., Laakso, L., Harrison, R. M., Hanson, I., Leung, C., Lehtinen, K. E. J., and Kerminen, V. M.: Toward direct measurement of atmospheric nucleation, Science, 318, 89-92, doi:10.1126/science.1144124, 2007.

Laj, P., Fuzzi, S., Facchini, M. C., Lind, J. A., Orsi, G., Preiss, M., Maser, R., Jaeschke, W., Seyffer, E., Helas, G., Acker, K., Wieprecht, W., Moller, D., Arends, B. G., Mols, J. J., Colvile, R. N., Gallagher, M. W., Beswick, K. M., Hargreaves, K. J., StoretonWest, R. L., and Sutton, M. A.: Cloud processing of soluble gases, Atmos. Environ., 31, 2589-2598, doi:10.1016/S1352-2310(97)00040-X, 1997a.

Laj, P., Fuzzi, S., Facchini, M. C., Orsi, G., Berner, A., Kruisz, C., Wobrock, W., Hallberg, A., Bower, K. N., Gallagher, M. W., Beswick, K. M., Colvile, R. N., Choularton, T. W., Nason, P., and Jones, B.: Experimental evidence for in-cloud production of aerosol sulphate, Atmos. Environ., 31, 2503-2514, doi:10.1016/S1352-2310(96)00217-8, 1997b.

Lelieveld, J. and Heintzenberg, J.: Sulfate Cooling Effect On Climate Through In-cloud Oxidation of Anthropogenic $\mathrm{SO}_{2}$, Science, 258, 117-120, doi:10.1126/science.258.5079.117, 1992.

Mariotti, A., Germon, J. C., Hubert, P., Kaiser, P., Letolle, R., Tardieux, A., and Tardieux, P.: Experimental-determination of Nitrogen Kinetic Isotope Fractionation - Some Principles - Illustration For the Denitrification and Nitrification Processes, Plant Soil, 62, 413-430, 1981.

Mauldin, R. L., Berndt, T., Sipila, M., Paasonen, P., Petaja, T., Kim, S., Kurten, T., Stratmann, F., Kerminen, V. M., and Kulmala, M.: A new atmospherically relevant oxidant of sulphur dioxide, Nature, 488, 193-197, doi:10.1038/nature11278, 2012.

Mertes, S., Galgon, D., Schwirn, K., Nowak, A., Lehmann, K., Massling, A., Wiedensohler, A., and Wieprecht, W.: Evolution of particle concentration and size distribution observed upwind, inside and downwind hill cap clouds at connected flow conditions during FEBUKO, Atmos. Environ., 39, 4233-4245, 2005 a.

Mertes, S., Lehmann, K., Nowak, A., Massling, A., and Wiedensohler, A.: Link between aerosol hygroscopic growth and droplet activation observed for hill-capped clouds at connected flow conditions during FEBUKO, Atmos. Environ., 39, 4247-4256, $2005 b$. 
Mitra, S., Brinkmann, J., and Pruppacher, H.: A wind tunnel study on the drop-to-particle conversion, J. Aerosol Sci., 23, 245-256, doi:10.1016/0021-8502(92)90326-Q, 1992.

Moore, K. F., Sherman, D. E., Reilly, J. E., and Collett, J. L.: Drop size-dependent chemical composition in clouds and fogs. Part I. Observations, Atmos. Environ., 38, 1389-1402, doi:10.1016/j.atmosenv.2003.12.013, 2004a.

Moore, K. F., Sherman, D. E., Reilly, J. E., Hannigan, M. P., Lee, T., and Collett, J. L.: Drop size-dependent chemical composition of clouds and fogs. Part II: Relevance to interpreting the aerosol/trace gas/fog system, Atmos. Environ., 38, 1403-1415, doi:10.1016/j.atmosenv.2003.12.014, 2004b.

Nel, A.: Air Pollution-Related Illness: Effects of Particles, Science, 308, 804-806, doi:10.1126/science.1108752, 2005.

Pierce, J. R., Evans, M. J., Scott, C. E., D'Andrea, S. D., Farmer, D. K., Swietlicki, E., and Spracklen, D. V.: Weak global sensitivity of cloud condensation nuclei and the aerosol indirect effect to Criegee $+\mathrm{SO}_{2}$ chemistry, Atmos. Chem. Phys., 13, 3163-3176, doi:10.5194/acp-13-3163-2013, 2013.

Pope, C. A. and Dockery, D. W.: Health Effects of Fine Particulate Air Pollution: Lines that Connect, J. Air Waste Manage., 56, 709-742, doi:10.1080/10473289.2006.10464485, 2006.

Rani, A., Prasad, D. S. N., Madnawat, P. V. S., and Gupta, K. S.: The Role of Free-fall Atmospheric Dust In Catalyzing Autoxidation of Aqueous Sulfur-dioxide, Atmos. Environ. A-Gen., 26, 667673, 1992.

Redington, A. L., Derwent, R. G., Witham, C. S., and Manning, A. J.: Sensitivity of modelled sulphate and nitrate aerosol to cloud, $\mathrm{pH}$ and ammonia emissions, Atmos. Environ., 43, 32273234, 2009.

Riemer, N., West, M., Zaveri, R., and Easter, R.: Simulating the evolution of soot mixing state with a particle-resolved model, J. Geophys. Res.-Atmos., 114, D09202, doi:10.1029/2008JD011073, 2009.

Roberts, G. C. and Nenes, A.: A continuous-flow streamwise thermal-gradient $\mathrm{CCN}$ chamber for atmospheric measurements, Aerosol Sci. Technol., 39, 206-221, doi:10.1080/027868290913988, 2005.

Sander, R., Lelieveld, J., and Crutzen, P. J.: Modelling of the nighttime nitrogen and sulfur chemistry in size resolved droplets of an orographic cloud, J. Atmos. Chem., 20, 89-116, 1995.

Sarwar, G., Fahey, K., Kwok, R., Gilliam, R., Roselle, S., Mathur, R., Xue, J., Yu, J., and Carter, W.: Potential impacts of two $\mathrm{SO}_{2}$ oxidation pathways on regional sulfate concentrations: Aqueous-phase oxidation by $\mathrm{NO}_{2}$ and gas-phase oxidation by stabilized Criegee intermediates, Atmos. Environ., 68, 186-197, doi:10.1016/j.atmosenv.2012.11.036, 2013.

Schwarzenboeck, A., Heintzenberg, J., and Mertes, S.: Incorporation of aerosol particles between 25 and $850, \mathrm{~nm}$ into cloud elements: measurements with a new complementary sampling system, Atmos. Res., 52, 241-260, doi:10.1016/S01698095(99)00034-4, 2000.

Seinfeld, J. H. and Pandis, S. N.: Atmospheric Chemistry and Physics, Wiley \& Sons, New York, 1998.

Sinha, B., Harris, E., Hoppe, P., Mertes, S., Gnauk, T., van Pinxteren, D., and Herrmann, H.: Source category specific CCN activation curves based on SEM and AFM single particle analysis from the Hill Cap Cloud Thuringia (HCCT) field experiments and the effect of cloud processing on the mixing state of accu- mulation mode aerosol: A combined SEM, AFM study during HCCT 2010, Atmos. Chem. Phys., in preparation, 2014a.

Sinha, B., Poehlker, C., Wiedemann, K., Harris, E., Hoppe, P., Kilcoyne, A., Andreae, M. O., Gunthe, S. S., Pöschl, U., and Borrmann, S.: Investigating the chemical composition and mixing state of secondary aerosol particles using NanoSIMS, Atmos. Meas. Tech., in preparation, 2014b.

Suhre, K., V, C., Mari, C., Rosset, R., Johnson, D. W., Osborne, S., Wood, R., Andreae, M. O., Bandy, B., Bates, T. S., Businger, S., Gerbig, C., Raes, F., and Rudolph, J.: Chemistry and aerosols in the marine boundary layer: 1-D modelling of the three ACE2 Lagrangian experiments RID B-1068-2008, Atmos. Environ., 34, 5079-5094, doi:10.1016/S1352-2310(00)00221-1, 2000.

Tilgner, A., Schöne, L., Bräuer, P., van Pinxteren, D., Hoffmann, E., Spindler, G., Mertes, S., Birmili, W., Otto, R., Merkel, M., Weinhold, K., Wiedensohler, A., Deneke, H., Haunold, W., Engel, A., Wéber, A., and Herrmann, H.: Critical assessment of meteorological conditions and airflow connectivity during HCCT-2010, Atmos. Chem. Phys. Discuss., 14, 1861-1917, doi:10.5194/acpd-14-1861-2014, 2014.

Tilly, J., Lewicki, M., Tomaszewski, Z., and Toczkowski, J.: Use of Ilmenite Decomposition Products In A Gas Desulfurization Process, J. Chem. Technol. Biot., 52, 301-310, 1991.

Twomey, S.: Aerosol, Clouds and Radiation, Atmos. Environ., 25A, 2435-2442, 1991.

USEPA: Air Quality Criteria for Particulate Matter, Report No. EPA/600/P-99/002aF and EPA/600/P-99/002bF, Tech. Rep., National Center for Environmental Assessment, Office of Research and Development, US Environmental Protection Agency, Washington, DC, 2004.

van Pinxteren, D., Birmili, W., Fomba, W., Gnauk, T., Iinuma, Y., Mertes, S., Mildenberger, K., Merkel, M., Mueller, C., Mueller, K., Poulain, L., Spindler, G., Henning, S., Stratmann, F., Tilgner, A., Wex, H., Wolke, R., Wiedensohler, A., Zhijun, W., Boettger, T., Borrmann, S., Harris, E., Roth, A., Schneider, J., Sinha, B., George, I., Heard, D. E., Whalley, L., D’Anna, B., George, C., Mueller, M., Amedro, D., Fittschen, C., Scheomaker, C., Collett, J., Lee, T., and Herrmann, H.: Hill Cap Cloud Thuringia 2010 - Overview and First Results, European Aerosol Conference, 2011.

Weber, R. J., Marti, J. J., McMurry, P. H., Eisele, F. L., Tanner, D. J., and Jefferson, A.: Measurements of new particle formation and ultrafine particle growth rates at a clean continental site, J. Geophys. Res.-Atmos., 102, 4375-4385, doi:10.1029/96JD03656, 1997.

Whalley, L., George, I., and Heard, D. E.: $\mathrm{OH}$ and $\mathrm{HO}_{2}$ measurements in and out of cloud during the HCCT-2010 campaign, Atmos. Chem. Phys., in preparation, 2014.

Winterholler, B., Hoppe, P., Andreae, M. O., and Foley, S.: Measurement of sulfur isotope ratios in micrometer-sized samples by NanoSIMS, Appl. Surf. Sci., 252, 7128-7131, 2006.

Winterholler, B., Hoppe, P., Foley, S., and Andreae, M. O.: Sulfur isotope ratio measurements of individual sulfate particles by NanoSIMS, Int. J. Mass Spectrom., 272, 63-77, 2008.

Yuskiewicz, B. A., Stratmann, F., Birmili, W., Wiedensohler, A., Swietlicki, E., Berg, O., and Zhou, J.: The effects of in-cloud mass production on atmospheric light scatter, Atmos. Res., 50, 265-288, 1999. 